\title{
The role of variable wind forcing in generating eddy energy in the North Atlantic
}

\author{
Detlef Stammer $^{\text {a,* }}$, Claus Böning ${ }^{\mathrm{b}}$, Christian Dieterich ${ }^{\mathrm{c}}$ \\ ${ }^{a}$ Department of Earth, Atmospheric and Planetary Sciences, Massachusetts Institute of Technology, Cambridge, \\ MA 02139, USA \\ ${ }^{\mathrm{b}}$ Institut für Meereskunde, Düsternbrooker Weg 20, 24105 Kiel, Germany \\ c Alfred-Wegener-Institut, Postfach 120161, D-27515 Bremerhaven, Germany
}

\begin{abstract}
Seasonal changes in eddy energy are used to investigate the role of high-frequency wind forcing in generating eddy kinetic energy in the oceans. To this end, we analyze two experiments of an eddy-permitting model of the North Atlantic driven by daily and monthly mean wind stress fields, and compare results with corresponding changes in the variance of the wind fields, and related results from previous studies using altimeter and current meter data.

With daily wind-stress forcing the model is found to be in general agreement with altimetric observations and reveal a complex pattern of temporal changes in variability over the North Atlantic. Observations and the model indicate enhanced levels of eddy energy during winter months over several areas of the northern and, particularly northeastern North Atlantic. Since the wind-generated variability is primarily barotropic, its signal can be detected mostly in the low-energy regions of the northern and north-eastern North Atlantic, which are remote from baroclinically unstable currents. There the winter-to-summer difference in simulated eddy kinetic energy caused by the variable wind forcing is $<0.5 \mathrm{~cm}^{2} \mathrm{~s}^{2}$ between $30^{\circ}$ and $55^{\circ} \mathrm{N}$, and is $1-$ $3 \mathrm{~cm}^{2} \mathrm{~s}^{2}$ north of $55^{\circ} \mathrm{N}$. Seasonal changes in kinetic energy are insignificant along the path of the North Atlantic current and south of about $30^{\circ} \mathrm{N}$.

The weak depth dependence of the seasonal changes in eddy energy implies that the relative importance of wind-generated eddy energy is maximum at depth where the general (baroclinic) variability level is low. Accordingly, a significant correlation is found between the seasonal cycle in the variance of wind stress and the seasonal cycle in eddy energy over a substantially wider area than near the surface, notably across the entire eastern North Atlantic between the North Atlantic Current and the North Equatorial Current. (C) 2001 Published by Elsevier Science Ltd.
\end{abstract}

\footnotetext{
* Corresponding author. Tel.: +1-858-822-3376; fax: +1-858-534-9820.

E-mail address: dstammer@ucsd.edu (D. Stammer).
} 


\section{Contents}

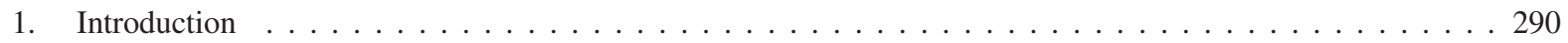

2. Recent observational evidence . . . . . . . . . . . . . . . . . . . . . . . . . . . . . 292

3. Model experiments . . . . . . . . . . . . . . . . . . . . . . . . . . . . . . 295

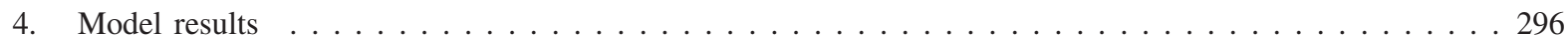

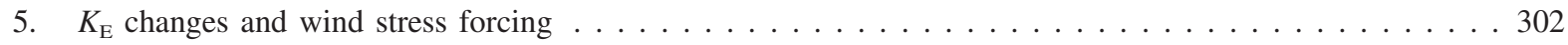

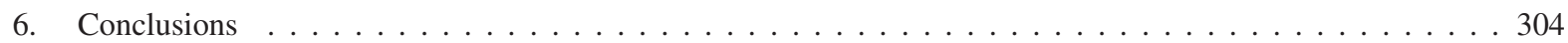

Acknowledgements . . . . . . . . . . . . . . . . . . . . . . . . . . . . . . 309

References . . . . . . . . . . . . . . . . . . . . . . . . . . . . . 309

\section{Introduction}

Despite substantial efforts over the last several years, many quantitative uncertainties remain about the distribution and causes of the mesoscale eddy field in the open ocean and its impact on the general circulation. Gill, Green and Simmons (1974) suggested that regions such as the Atlantic North Equatorial Current may be baroclinically unstable, and so act as a local source of eddy energy for the large-scale ocean circulation, remote and independent from unstable boundary currents. However, a field study (Fu, Keffer, Niiler \& Wunsch, 1982) failed to confirm this hypothesis, and later observations failed to produce unequivocal evidence for any simple baroclinic instability hypothesis in the open sea (e.g., Mercier \& Colin de Verdiere, 1985).

Nevertheless, satellite altimetry and high-resolution numerical models do indicate that there is a close association between the observed eddy kinetic energy distributions with the (local) mean baroclinic flow field (Beckmann, Böning, Brügge \& Stammer, 1994; Wunsch \& Stammer, 1995; Stammer \& Böning, 1996). Moreover, the observed mesoscale wavenumber characteristics are generally consistent with geostrophic turbulence and associated eddy scales being strongly correlated with the first mode Rossby radius of deformation (Stammer, 1997). All this together with independent results from current meter data (Wunsch, 1997) support the hypothesis that mean flow instabilities are a primary cause for the observed eddy energy levels over most areas of the mid-latitude oceans.

An alternative theory — that of mesoscale eddies being generated by fluctuating winds — was pioneered by Frankignoul and Müller (1979) and Müller and Frankignoul (1981) in developing a linear stochastic model that was able to predict the spectral properties of the quasigeostrophic ocean response to prescribed wind stress curl spectra. The effectiveness of this mechanism has been under debate, however, because the resulting energy level fundamentally depends on details of assumed friction processes in the ocean and on the prescribed power spectrum of the near surface winds at high frequencies and high wavenumbers (Large, Holland \& Evans, 1991).

Forced by high-frequency winds (time scales from days to weeks) the ocean predominantly 
responds in the form of barotropic Rossby waves (Willebrand, Philander \& Pacanowski, 1980). Several studies (e.g. Fu \& Smith, 1996; Fukumori, Raghunath \& Fu, 1998) have illustrated that barotropic Rossby waves are excited by high-frequency wind fluctuations in several regions of the world oceans, notably the South-East Pacific and the northern North Pacific. Observational support for the existence of wind-induced, barotropic current fluctuation also results from significant (nonlocal) coherences between deep ocean currents and the wind stress curl fluctuation at various mooring sites in the North Atlantic (Brink, 1989; Samelson, 1990) and North Pacific (Luther, Chave, Filloux \& Spain, 1990; Chave, Luther \& Filloux, 1992; see also Niller \& Koblinsky, 1982, 1985; Koblinsky, Niiler \& Schmitz, 1989). But the degree to which wind fluctuations are responsible for observed near-surface energy levels is still not fully understood as a function of geographical position and depth.

Insights into the contributions of fluctuating wind stress fields to the generation of eddy kinetic energy may be obtained by examining seasonal changes in the eddy kinetic energy $\left(K_{\mathrm{E}}\right)$. The intensity of synoptic atmospheric disturbances over the mid- and high-latitude oceans exhibits a pronounced seasonal cycle, with a variance maximum in winter and minimum in summer; hence the presence of a similar seasonal cycle in $K_{\mathrm{E}}$ and its phase relation to the wind stress variance should provide a useful indicator that such a generation mechanism exists. A problem, however, lies in the fact that a direct effect of wind forcing and its consequential seasonal change in eddy energy may be masked by other indirect effects resulting from seasonal modulation of the current systems and its internal flow instability. Here we aim to understand and to separate the cause and effect of both eddy generation processes.

The first indication of a seasonal variation in levels of the eddy kinetic energy was by Dickson, Gould, Gurbutt and Killworth (1982), who reported a winter $K_{\mathrm{E}}$ maximum in current meter records at a few sites in the northeastern North Atlantic, east of $20^{\circ} \mathrm{W}$. They interpreted their findings as evidence for direct wind effects on eddy generation, but neither they nor Müller and Siedler (1992) were able to detect any significant seasonal variation in current meter records from sites located further south in the eastern North Atlantic. A conflicting result concerning temporal changes in eddy kinetic energy was also obtained from surface drifter data. Richardson (1983) reported the occurrence of $K_{\mathrm{E}}$ maximum during spring (May/June) along the North Atlantic Current (NAC) (between $40^{\circ} \mathrm{N}-54^{\circ} \mathrm{N}$ and $10^{\circ} \mathrm{W}-38^{\circ} \mathrm{W}$ ), about 4 months after the maximum in wind stress. The energy minimum for this area was obtained for August/September. Further west along the eastern Gulf Stream $\left(38^{\circ} \mathrm{N}-42^{\circ} \mathrm{N}, 45^{\circ} \mathrm{W}-52^{\circ} \mathrm{W}\right)$, Richardson found a minimum in July/August and maximum in autumn/spring. In contrast to these findings, Brügge (1995), using an improved drifter data set with increased coverage and enhanced data quality control, reported a variability maximum along the NAC (at $30^{\circ} \mathrm{W}$ ) during winter, preceded by a minimum in fall. A different phase, with a maximum in fall, was abtained for the Azores Current regime.

Previous difficulties in studies of eddy generation mechanisms resulting from inadequate data coverage have recently been ameliorated to some extent through the availability of continuous and global altimeter data sets. (For a recent review on altimetric results regarding temporal changes in ocean circulation see Wunsch \& Stammer, 1998.) Of particular relevance to this study are firstly the analysis of seasonal and interannual changes in $K_{\mathrm{E}}$ over the subpolar North Atlantic to the north of $40^{\circ} \mathrm{N}$ by White and Heywood (1995) who used 4 years of GEOSAT and TOPEX/POSEIDON (T/P) data, and secondly the extensive analysis of the changes in oceanic variability on annual and interannual time scales by Stammer and Wunsch (1999) (SW99, 
hereafter), using the global T/P data set. The hypothesis that there is a significant wind effect appears to be consistent with the altimetric data for the northern North Atlantic but not for the subtropical gyre. However, in these analyses based solely on observational data the question regarding the detailed quantitative role of a direct wind-generation mechanisms and its significance in different regions had to be left open, because complex patterns of the temporal changes in eddy variability and the corresponding wind stress fields.

In this paper the effect of a high-frequency wind forcing on the observed eddy energy is examined in a way complimentary to SW98. This study is based on a comparison of eddy statistics from two eddy-permitting model runs that have been set-up in the DYNAMO modeling framework (The DYNAMO Group, 1997) and that differ only in their wind forcing (monthly-mean ECMWF climatology versus daily ECMWF wind stress fields; see Section 3 for details on the model setups). Differences in the eddy statistics derived from these runs will be used to address the following questions:

1. Do we find a time-varying eddy kinetic energy signal in the models similar to observed variations?

2. What is its horizontal and vertical structure and its relation to atmospheric forcing?

3. Can we identify significant changes in simulated levels of eddy energy when changing wind stress forcing from a monthly climatology to daily fields? If so, where?

Answers to those questions are required to refine previous conclusions drawn about causes for observed changes in eddy energy levels over the North Atlantic. We will start in Section 2 with a summary of current observational evidence for temporal changes of eddy kinetic energy, specifically focussing on SW99. Relevant aspects of the model experiments will be summarized in Section 3. The eddy statistics simulated by the model and its relation to the observations will be discussed in Section 4. Seasonal variations of $K_{\mathrm{E}}$ in the model and its correspondence to the observed behavior are discussed in Section 5, followed by conclusions in Section 6 .

\section{Recent observational evidence}

In an analysis of 4 years of GEOSAT and TOPEX/POSEIDON (T/P) data from north of $40^{\circ} \mathrm{N}$ in the Atlantic Ocean, White and Heywood (1995) reported basin-average $K_{\mathrm{E}}$ variations on annual period of about $20 \mathrm{~cm}^{2} \mathrm{~s}^{2}$, with a maximum in winter. These changes were more pronounced in the areas where background $K_{\mathrm{E}}$ amplitudes were weaker away from the North Atlantic Current (NAC). There was very little phase lag between $K_{\mathrm{E}}$ and wind stress maxima, from which the authors concluded that in these areas the eddies are primarily driven by the local wind stress. However, the relative seasonal variation was found to be weak along the NAC, indicating that there the intense eddy fields are primarily the product of instability mechanisms.

This latter finding was confirmed in a global analysis of the T/P data set by SW99. They showed that seasonal variations in $K_{\mathrm{E}}$ are negligible (compared to the mean) in major frontal areas and in most of the subtropical oceans, where the patterns of energy change appear closely related to intense current features, with no obvious direct link with annual changes in the wind field. 
Defining the surface slope anomaly as $\gamma=\partial \eta^{\prime} / \partial s$, where $s$ is the along-track distance and $\eta^{\prime}$ is the anomaly of sea surface height relative to a time-mean, the eddy kinetic energy follows from the along-track altimeter data as

$$
K_{\mathrm{E}}=(g /(2 \Omega \sin (\phi)))^{2}\left\langle\gamma^{2}\right\rangle
$$

with $\varphi$ being the latitude, $\Omega$ being the rotational frequency of the Earth, and $\langle\cdot\rangle$ indicating a time average. Alternatively, an equivalent slope variance $K_{\mathrm{S}}=\sin ^{2}(\varphi) K_{\mathrm{E}}$ has been used as a substitute for the geostrophic kinetic energy, because it can be computed without the singularity generated by the vanishing Coriolis parameter at the equator. Fields of $K_{\mathrm{E}}$ and $K_{\mathrm{S}}$ from 5 years of T/P data (SW99) are shown in Fig. 1, for the North Atlantic over regions with water depths $>1000 \mathrm{~m}$. 'Noise' on scales $<30 \mathrm{~km}$ was removed from the $\eta$ fields by a low-pass filter (Stammer, 1997); results were gridded onto a $2^{\circ}$ geographical grid before plotting. The close relation between the geographic $K_{\mathrm{S}}$ distribution and the path of the mean baroclinic circulation seen clearly in the figure has been studied in some detail (Stammer, 1997, 1998).

Fields like those shown in Fig. 1 have been computed on a monthly basis and used subsequently to least-square fit an annual harmonic together with a secular trend-modeled here as a harmonic with 8 year period. The resulting amplitude and phase of the annual harmonic of the eddy kinetic energy field are given in Fig. 2a and Fig. 2b, respectively. Maximum amplitudes of up to $200 \mathrm{~cm}^{2}$ $\mathrm{s}^{2}$ are located along the western boundary current and enhanced amplitudes occur throughout the area of the NECC, especially in the north-eastern North Atlantic and the Labrador Sea. A typical amplitude is $30-40 \mathrm{~cm}^{2} \mathrm{~s}^{2}$ in the Labrador Sea and the eastern North Atlantic. In terms of the percentage of the pure annual harmonic (as opposed to non-harmonic seasonal changes) relative to the total energy (Fig. 2c), most of the variations in the subtropical gyre and the Gulf Stream area are below $15 \%$ and show no obvious relation to the local wind stress forcing cycle. However, at a few locations, notably in the subpolar and north-eastern North Atlantic, seasonal $K_{\mathrm{S}}$ variations are substantial (up to $30 \%$ of the mean background level), and are almost in phase with the local wind stress forcing.

(a)

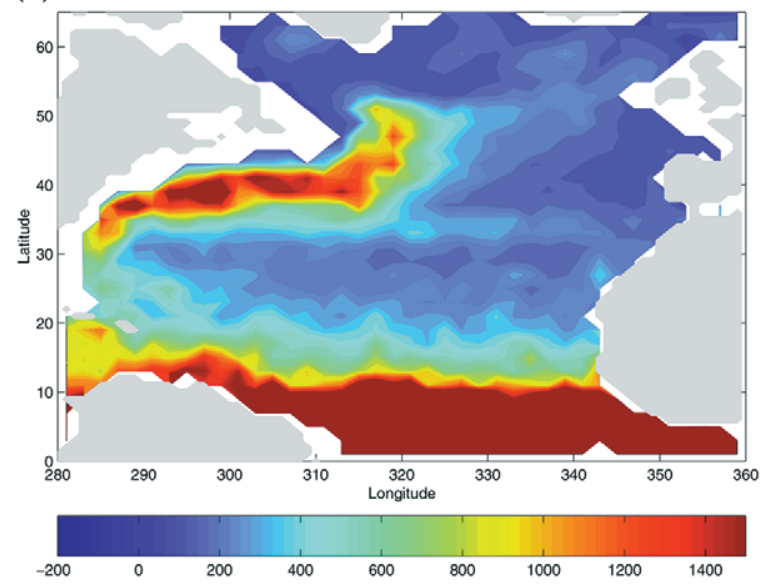

(b)

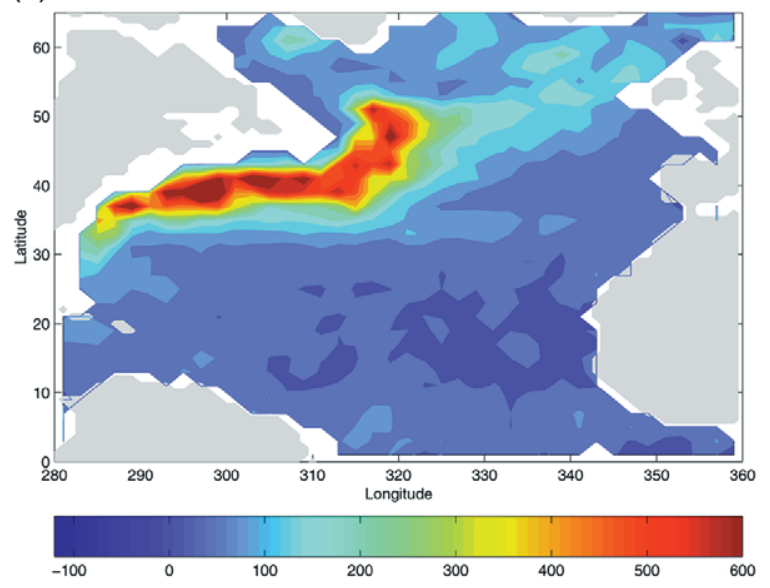

Fig. 1. $K_{\mathrm{E}}$ and $K_{\mathrm{S}}$ fields as they result from four years of TOPEX/POSEIDON along-track data and after gridding on a $2^{\circ}$ grid; water depths greater than $1000 \mathrm{~m}$ only (see text and Stammer, 1997, for details). 
(a)

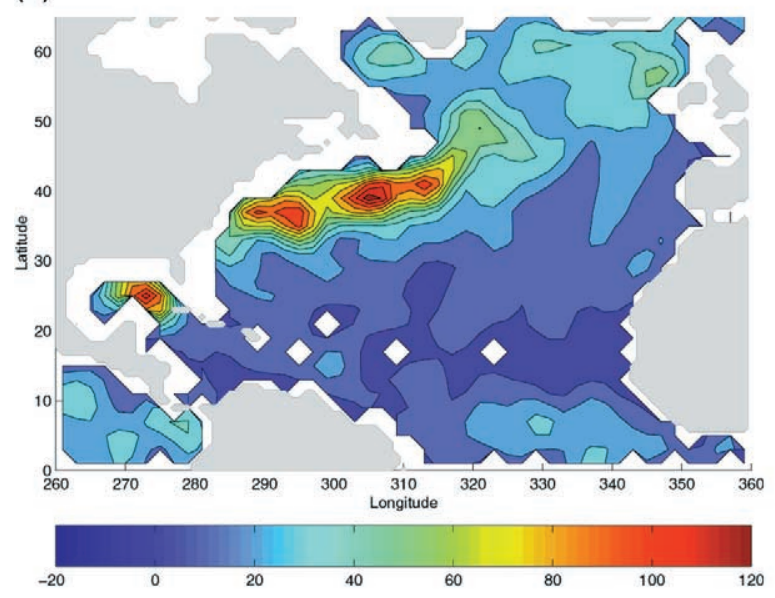

(b)

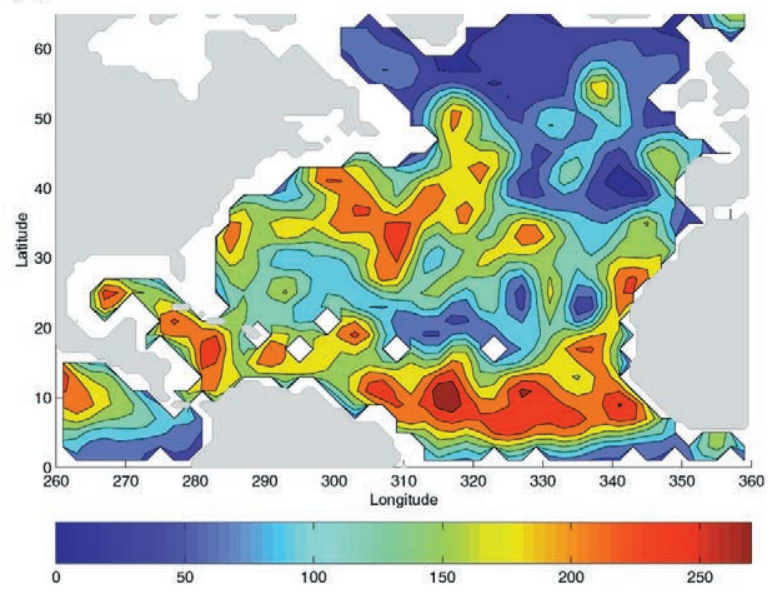

(c)

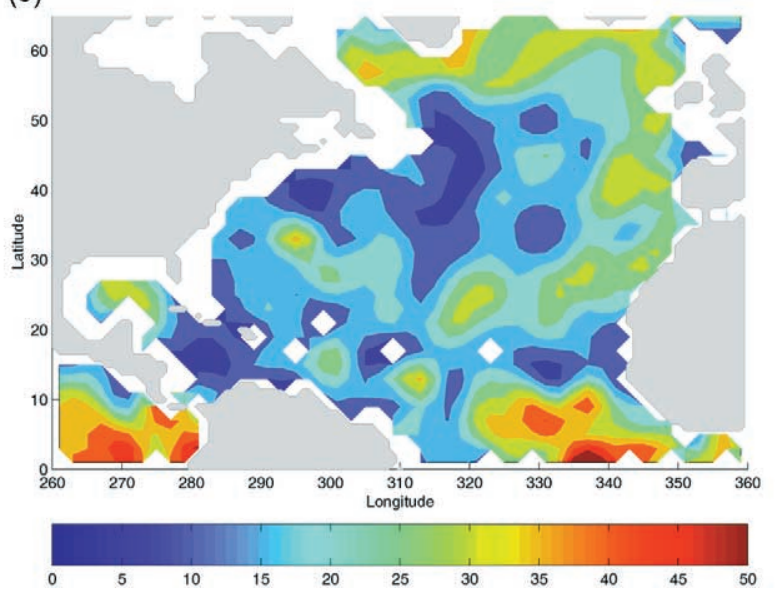

Fig. 2. The seasonal cycle of $K_{\mathrm{S}}$ estimated from monthly $K_{\mathrm{S}}$ fields. Shown are (a) the amplitude in $\mathrm{cm}^{2} \mathrm{~s}^{2}$, (b) the phase in ${ }^{\circ} \mathrm{s}$ relative to January 1 , and (c) the percentage the amplitude is of the mean variability.

Enhanced amplitudes of secular $K_{\mathrm{E}}$ changes occur along most of the Gulf Stream and North Atlantic Current, as well as in the central Labrador Sea (Fig. 3a). There is a remarkable phase shift in the variability of about $180^{\circ}$ between the subtropical and sup-polar gyres (Fig. 3b). Over the T/P period the entire sub-polar gyre experienced a substantial decrease in energy that coincided with a similar decrease in wind stress. At the same time the Gulf Stream variability increased somewhat. SW99 illustrated that these changes are consistent with high-latitude NAO-type variations in wind stress forcing and associated shifts in the atmospheric storm patterns. However, the simultaneous changes in mean sea level suggested that there was a change in the mean ocean circulation with an associated strengthening of the Gulf Stream and its extension (as a response to shifting wind fields) which, in turn, could result in changes in oceanic variability.

Although the findings of SW99 for the northeastern North Atlantic are roughly consistent with the results of Dickson et al. (1982) and White and Heywood (1995), they emphasize the complex 
(a)

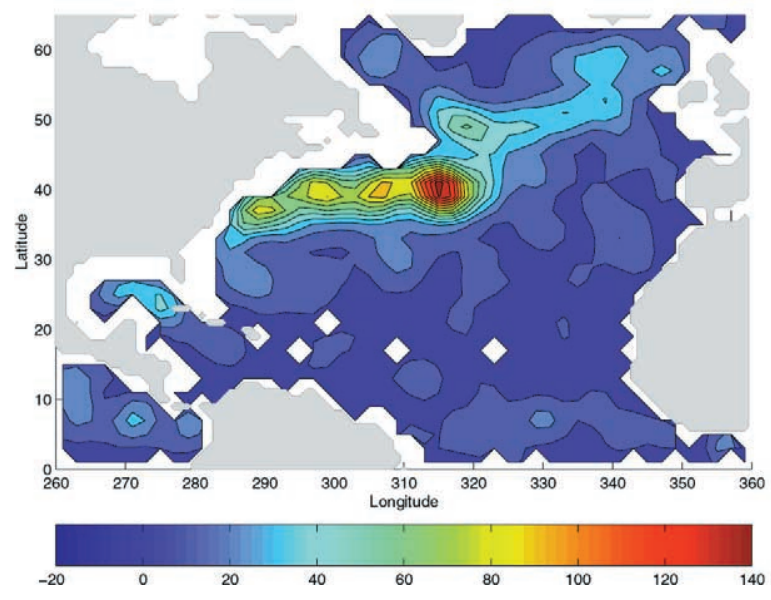

(b)

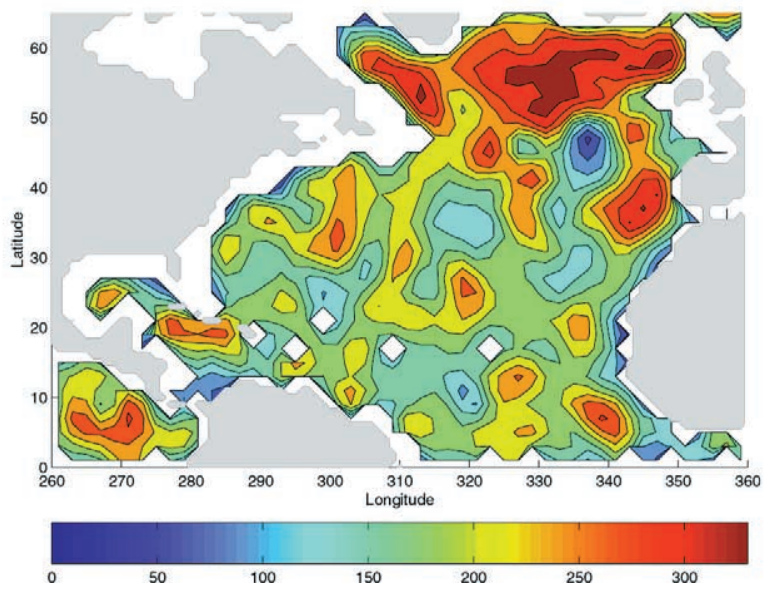

Fig. 3. Long-term changes in $K_{\mathrm{S}}$ estimated as a harmonic with 8 year period fitted to monthly $K_{\mathrm{S}}$ fields simultaneous with the annual cycle. Shown are (a) the amplitude in $\mathrm{cm}^{2} \mathrm{~s}^{2}$, (b) the phase in ${ }^{\circ} \mathrm{s}$ relative to January 1.

spatial pattern of $K_{\mathrm{E}}$ and its temporal changes on both annual and interannual periods. In particular the conclusion drawn by Dickson et al. (1982) "that the wind is responsible for most of the observed open-ocean eddy variability (remote from boundary currents)" is not supported by the altimetric results. Instead, direct wind impact seems to be limited to very high latitudes and the north-eastern Atlantic; and even there, only a fraction of the observed eddy energy in the altimeter data appears to be related directly to the wind stress.

\section{Model experiments}

The main purpose of the DYNAMO program (DYNAMO Group, 1997) was the inter-comparison of three eddy-permitting primitive equation models with its main emphasis on the simulation of the large-scale circulation (Willebrand et al., 2001) and the representation of physical mechanisms in different flow regimes (Barnier et al., 2001; New, Barnard, Herrmann \& Molines, 2001a; New, Jia, Coulibaly \& Dengg, 2001b; Böning, Dieterich, Barnier \& Jia, 2001). All the models were applied to basically identical conditions in the Atlantic Ocean between $20^{\circ} \mathrm{S}$ and $70^{\circ} \mathrm{N}$, with a spatial resolution of $\Delta \lambda=1 / 3^{\circ}$ in longitude, and $\Delta \varphi=\cos (\varphi) / 3^{\circ}$ in latitude.

They were all driven by climatological, monthly mean forcing fields, but differed in their discretization of the vertical coordinates. A detailed description of the model configuration and experimental strategy is provided by Willebrand et al. (2001).

In this study results obtained with the DYNAMO 'LEVEL' model (based on the MOM code; see Pacanowski, Dixon and Rosati (1991) for details) is used to discriminate between the generation of eddies directly by wind and internal flow instability mechanisms. We will use two runs, which will differ only in their external wind stress forcing conditions: Experiment 1 was forced with monthly climatological European Centre for Medium-Range Weather Forecasts (ECMWF) analysis fields obtained from the period 1986-1988 (see Willebrand et al., 2001). The 
model was spin-up over 15 years, and the subsequent 4 years are used as the main analysis period. Its result will be compared with a second run (Experiment 2, hereafter) in which the forcing is by daily ECMWF wind stress fields for the period 1990-1993.

During Experiment 1, instantaneous model fields (snapshots) were sampled every third day and from these seasonal means of $K_{\mathrm{E}}$ were computed, as well as its correlation with seasonal variations in the wind stress. However, in the case of the high-frequency wind forcing of Experiment 2 a different sampling strategy was required to avoid aliasing the energy from inertial frequencies into the eddy-kinetic energy field (Jayne \& Tokmakian, 1997). This was accomplished by estimating eddy statistics on the basis of 3-day averages of model fields, rather than snapshots on threeday intervals,

\section{Model results}

Fig. 4a shows the mean $K_{\mathrm{E}}$ field that resulted from Experiment 2 at a depth of $91 \mathrm{~m}$. There are obvious differences relative to T/P results at low latitudes where the enhanced values in Fig. 1a to some extent reflect data errors, and also along the path of the NAC, which is shifted eastward by about $10^{\circ}$ in the model and thus does not reproduce the observed northward turn at $45^{\circ} \mathrm{W}$ and its subsequent eastward turn roughly at $50^{\circ} \mathrm{N}$. Otherwise, the simulated amplitudes and spatial structures are comparable to the observations. In particular, the local energy maxima in the northeastern Atlantic, associated with the branches of the NAC through the Irminger Basin, the Iceland Basin, and Rockall Trough, are consistent with observations (compare Fig. 1) and reflect the

(a)

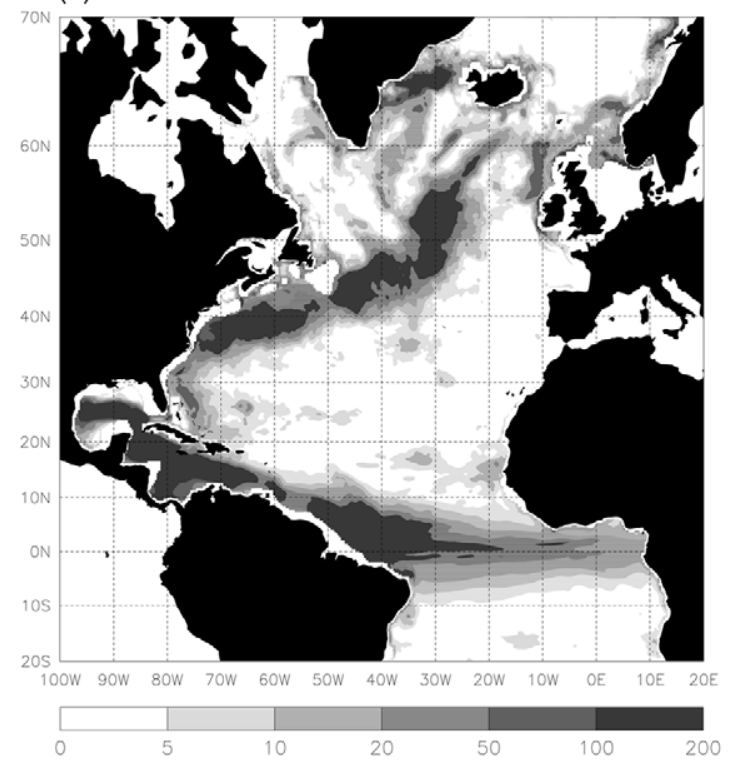

(b)

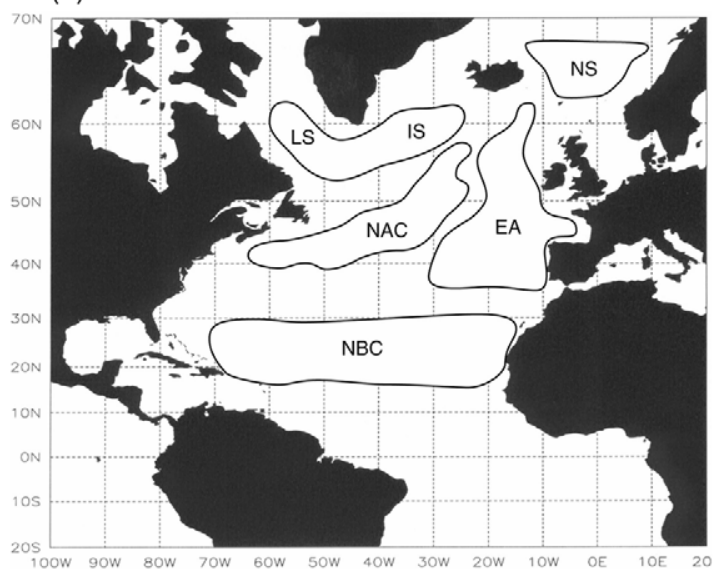

Fig. 4. (a) Mean $K_{\mathrm{E}}$ from four years of model velocity fields (1990-1993) from Experiment 2, at $91 \mathrm{~m}$ depth. Units are $(\mathrm{cm} / \mathrm{s})^{2}$. In (b), those regions are marked in which we will analyze seasonal changes in $K_{\mathrm{E}}$ below (see also Table 1 ). 
apparent role of the topographic structures in steering the large-scale flow in these particular portions of the basin (cf. White \& Heywood, 1995).

Vertical sections of $K_{\mathrm{E}}$ are shown in Fig. 5 along $58^{\circ} \mathrm{N}, 51^{\circ} \mathrm{N}$, and $30^{\circ} \mathrm{W}$, respectively. The energy is surface-intensified and concentrated along the NAC, which crosses the Mid-AtlanticRidge (MAR) at about $50^{\circ} \mathrm{N}$, and then splits into several branches heading northeast over the

(a)
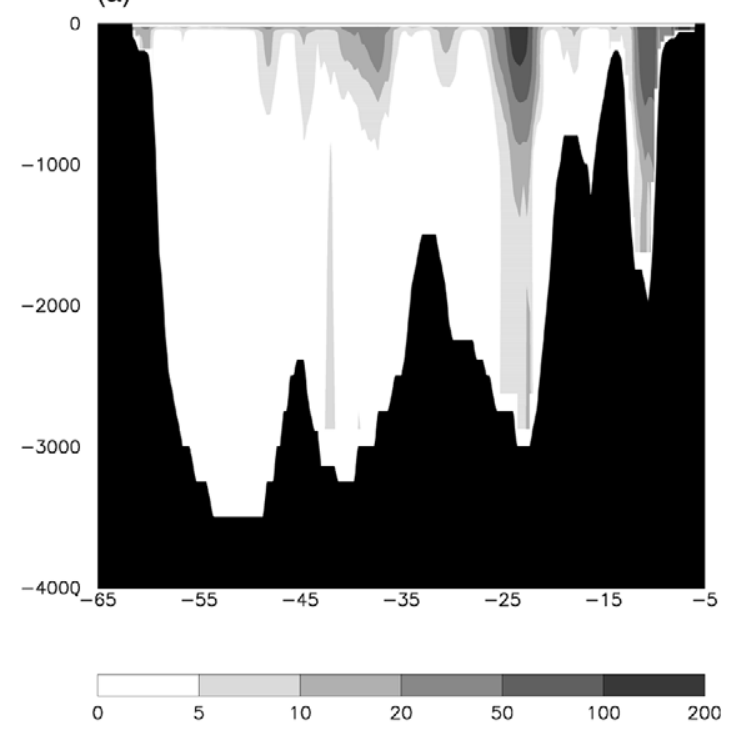

(b)

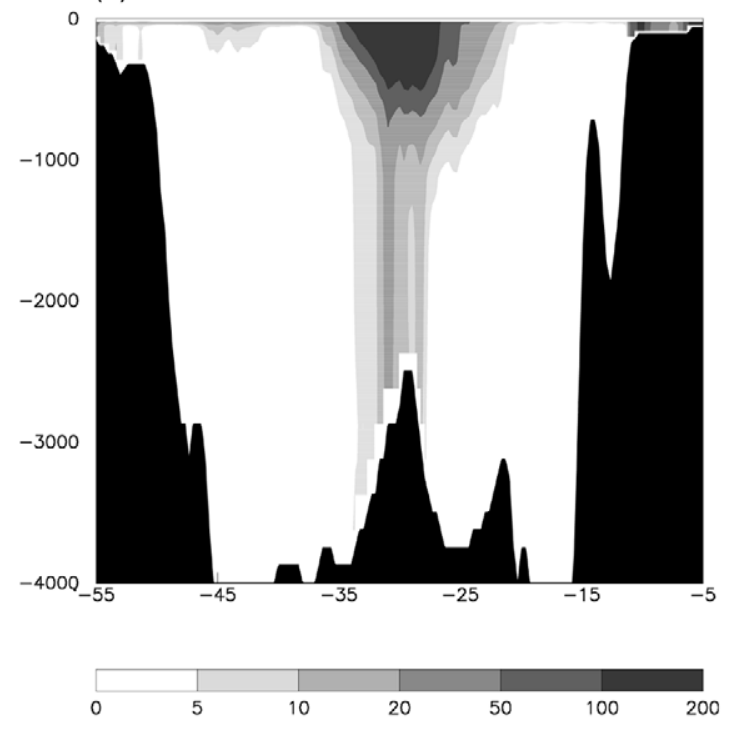

(c)

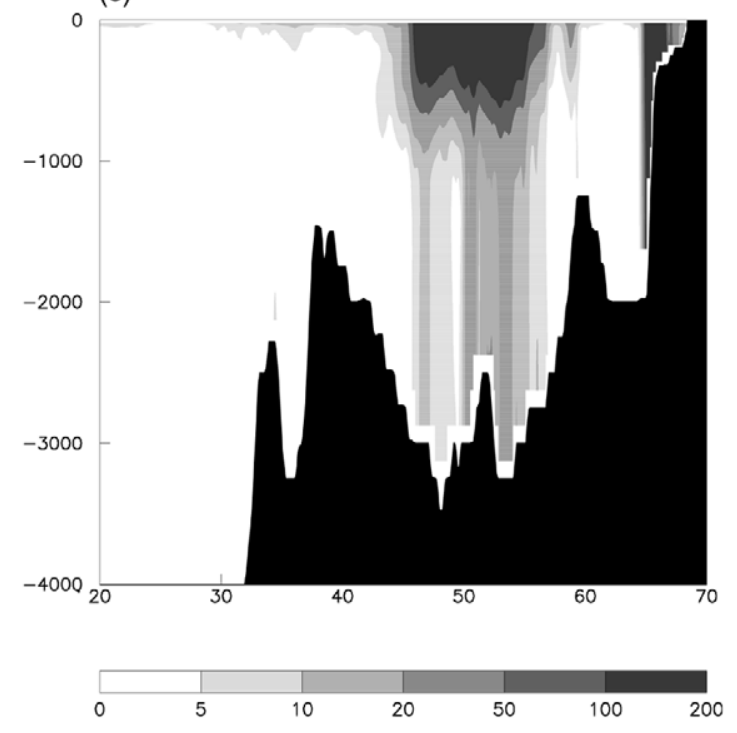

Fig. 5. Vertical sections of the same field shown in Fig. 4 a along $58^{\circ} \mathrm{N}, 51^{\circ} \mathrm{N}$ and $30^{\circ} \mathrm{W}$, respectively. Units are $(\mathrm{cm} / \mathrm{s})^{2}$. 
deeper parts of the basin. The important point to note is the absence of a general relation between $K_{\mathrm{E}}$-levels and bottom topography: it is the course of the mean flow field, which determines the energy distribution and accordingly may show either higher or lower values over topographic features (in this case, the MAR). Anticipating later results, two regions stand out: the Rockall Trough and, in particular, the continental slope off Greenland south of Denmark Strait, where there is very little decrease of $K_{\mathrm{E}}$ with depth, which is indicative of a predominantly fast barotropic character of the fluctuations.

For an analysis of the seasonal variation of $K_{\mathrm{E}}$, we will discriminate between those areas of high eddy energy, which are dominated by mean flow instabilities, and low energy areas, where eddy generation may be more prone to variability in wind forcing. The regions are schematically depicted in Fig. 4b and listed in Table 1. Shelf regions with water depth of $H<1000 \mathrm{~m}$ have been omitted from all areas; seasons are defined as follows: spring — AMJ, summer — JAS, fall OND and winter - JFM (note that this corresponds to a one month phase shift as compared to SW99).

The primary high-energy area represents the NAC north of $30^{\circ} \mathrm{N}$ and east of $60^{\circ} \mathrm{W}$ where $K_{\mathrm{E}}$ levels exceed $100 \mathrm{~cm}^{2} \mathrm{~s}^{2}$. Another potentially unstable current regime is the North Equatorial Current (NEC). However, in both Experiment 1 and Experiment 2, it exhibits only a weak enhancement of $K_{\mathrm{E}}$, not exceeding $50 \mathrm{~cm}^{2} \mathrm{~s}^{2}$. The criterion for selecting low-energy areas is where $K_{\mathrm{E}}$ is less than $50 \mathrm{~cm}^{2} \mathrm{~s}^{2}$. These are in the Labrador Sea (LS), the Irminger Sea (IS), the Norwegian Sea (NS) and the northern $\left(\mathrm{NEA}_{\mathrm{N}}\right)$ and southern $\left(\mathrm{NEA}_{\mathrm{S}}\right)$ regions of the North-East Atlantic. For the LS and IS a lower threshold value for $K_{\mathrm{E}}$ was chosen to eliminate some spurious effects of local bottom-intensified structures in the seasonal $K_{\mathrm{E}}$ profiles which arise from the interactions of the flow field with local topographic features and that otherwise would mask the signatures of the eddy generation mechanisms of interest here.

From the area-mean profiles of $K_{\mathrm{E}}$, shown in Figs. 6-12 as a function of season and depth for Experiment 1 (left column) and Experiment 2 (right column), a few generalizations can readily be made. Most important, we find no evidence of a significant seasonal variation in $K_{\mathrm{E}}$ over the NEC area, and there is only some slight indications of increased near-surface $K_{\mathrm{E}}$ levels during fall and winter over the NAC, in both Experiment 1 and Experiment 2.

Energies in the top $600 \mathrm{~m}$ generally appear higher in case of daily wind stress forcing (Experiment 2) as compared to climatalogical forcing conditions (Experiment 1). We believe that this general increase in the energy level between the two experiments by about $40 \mathrm{~m}^{2} \mathrm{~s}^{2}$ (or 20\%)

Table 1

Regional sub-division

\begin{tabular}{lll}
\hline Label & Region & Energy \\
\hline NAC & High energy regions & $K_{\mathrm{E}}>100 \mathrm{~cm}^{2} / \mathrm{s}^{2}$ \\
NEC & North Equatorial Current & $K_{\mathrm{E}}<50 \mathrm{~cm}^{2} / \mathrm{s}^{2}$ \\
LS & Labrador Sea & $K_{\mathrm{E}}<20 \mathrm{~cm}^{2} / \mathrm{s}^{2}$ \\
IS & Irminger Sea & $K_{\mathrm{E}}<20 \mathrm{~cm}^{2} / \mathrm{s}^{2}$ \\
NS & Norwegian Sea & $K_{\mathrm{E}}<50 \mathrm{~cm}^{2} / \mathrm{s}^{2}$ \\
NEA & Northern North-East Atlantic & $K_{\mathrm{E}}<50 \mathrm{~cm}^{2} / \mathrm{s}^{2}$ \\
NEA $_{\mathrm{S}}$ & Southern North-East Atlantic & $K_{\mathrm{E}}<50 \mathrm{~cm}^{2} / \mathrm{s}^{2}$ \\
\hline
\end{tabular}



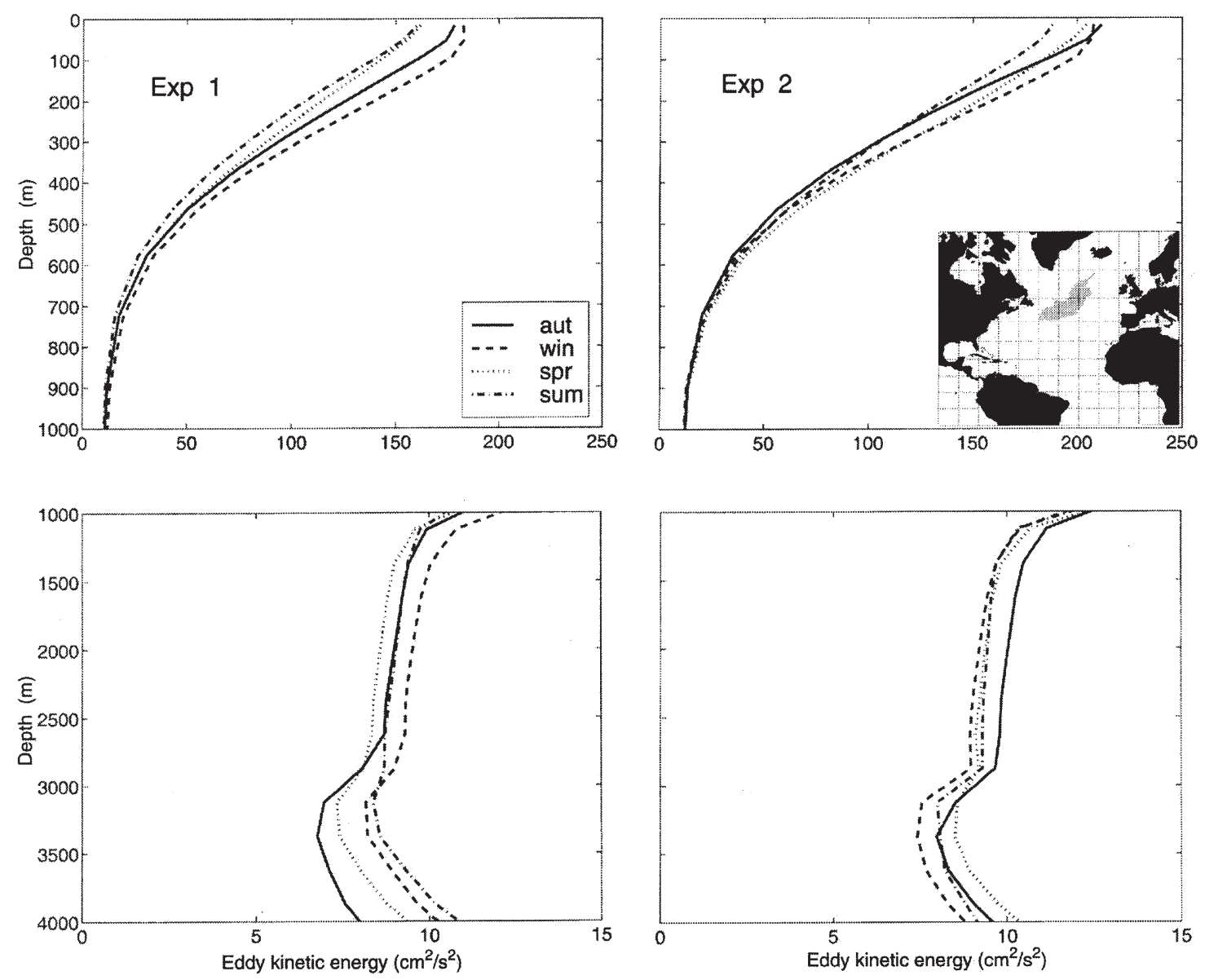

Fig. 6. Seasonal profiles of $K_{\mathrm{E}}$ for the NAC region. The left column shows results from Experiment 1 for two different depth ranges. Curves for spring, summer, autumn, and winter are labeled. The right column shows similar results from Experiment 2 and the area represented in the panels is shown in the inset.

reflects changes in the mean atmospheric conditions during two different periods of the atmospheric state: 1986-88 for Experiment 1 and 1990-1993 for Experiment 2. To support this statement, in Fig. 13a we show zonal averages of the $\left|\tau_{\kappa}\right|$ values from all summer month of Experiment 1 and Experiment 2, averaged between $20^{\circ} \mathrm{W}$ and $60^{\circ} \mathrm{W}$. The mean wind stress is substantially higher during the second experiment, which is consistent with an increase in the oceanic flow field and an enhancement in associated instability processes. It is interesting to note that a similar increase in $K_{\mathrm{E}}$ was observed by SW99 in the NAC region during the T/P mission period (compare Fig. 3).

In contrast to the NAC and NEC regimes, there is a significant impact of the daily wind forcing on the seasonal cycle of eddy energy in all low energy regions at mid- and higher latitudes:

NEAs: While we can detect no seasonality in fields from Experiment 1 in this area, the deep layers show a clear seasonal cycle when forced with daily wind stress fields (Experiment 2). A 

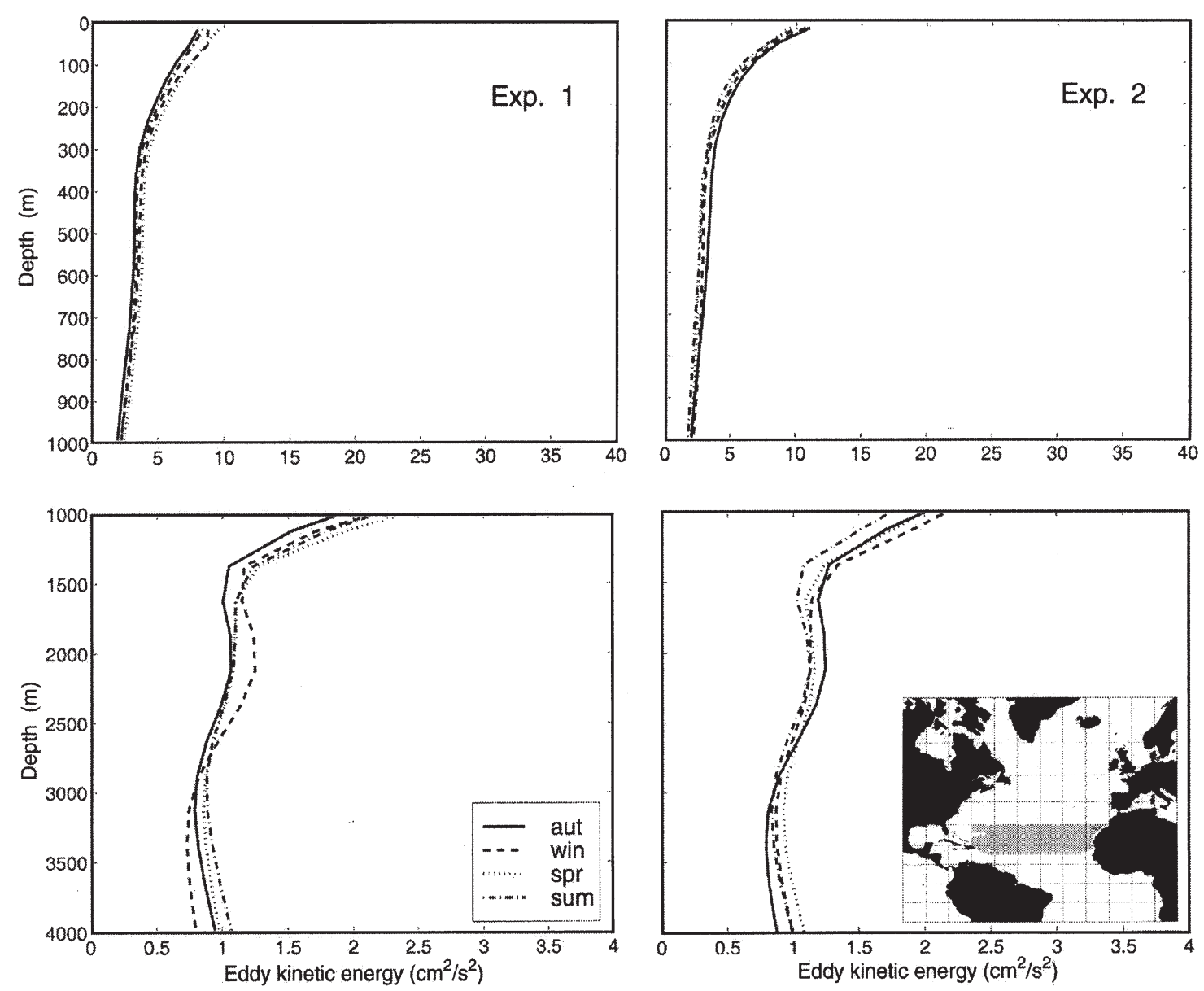

Fig. 7. Seasonal profiles of $K_{\mathrm{E}}$, similar to Fig. 6, but for the NEC region.

maximum in energy occurs in fall and winter, whereas that during the rest of the year is lower by more than $50 \%$.

NW: Here a similar, but even stronger effect than in the NEA $_{S}$ area can be seen, with the maximum of energy shifted towards winter. Note that this effect actually holds almost up to the surface.

$\mathrm{NEA}_{\mathrm{N}}$ : This area is intermediate in its seasonality of $K_{\mathrm{E}}$ between the changes found for NS and NEA $_{s}$. It shows additional local (topographic) effects at depth. The effects of the daily wind stress fields on $K_{\mathrm{E}}$ are seen throughout almost the entire water column down to about $3000 \mathrm{~m}$, but quite surprisingly not below.

LS: Essentially this area exhibits the same seasonal cycle as in the NS and NEA regions. There is a maximum in fall/winter and minimum during summer, but in contrast to the other areas in Experiment 1 there is a strong seasonal cycle with a summer maximum and a minimum during fall/winter. The effect of daily wind forcing is apparently to reverse this phase. The physical basis for this seasonality in Experiment 1 is unknown at this stage. However, we hypothesise that local 

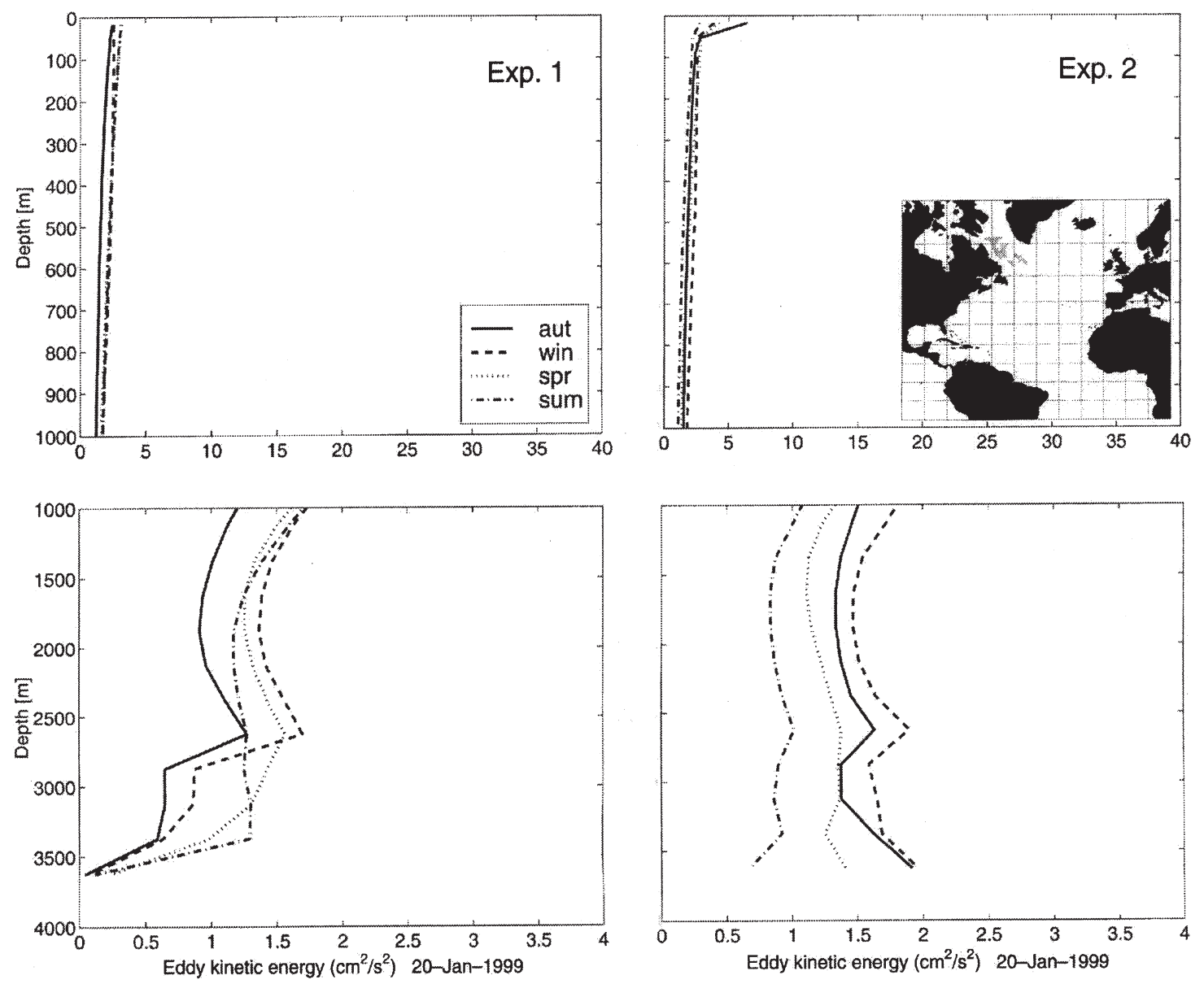

Fig. 8. Seasonal profiles of $K_{\mathrm{E}}$, similar to Fig. 6, but for region LS.

circulation changes in the LS resulting from changes in surface buoyancy fluxes and deep winterconvection are responsible for this competing effect. This is corroborated by the third test run, in which the wind forcing was switched off for a 3 year period, while all other parameters, initial and boundary conditions were kept the same. During this 'spin-down', a seasonal cycle similar to that in Experiment 1 was obtained. This suggests that surface cooling, subsequent convection and baroclinic instability mechanisms play a significant role in setting the seasonal energy cycle in that area. A detailed discussion of deep convection and subsequent restratification and adjustment processes in his area is provided by Marshall and Schott (1999).

IS: This area shows similar wind effects in the upper $2000 \mathrm{~m}$ to those in LS and further east, with a winter maximum and and a summer minimum. However, there is a pronounced energy increase at about $3000 \mathrm{~m}$ depth with a maximum in summer. This intensification is also present in the climatological run (Experiment 1) and is probably related to spurious variations in the deep boundary currents.

In summary: while the high frequency wind variability has a negligible impact on the seasonal 

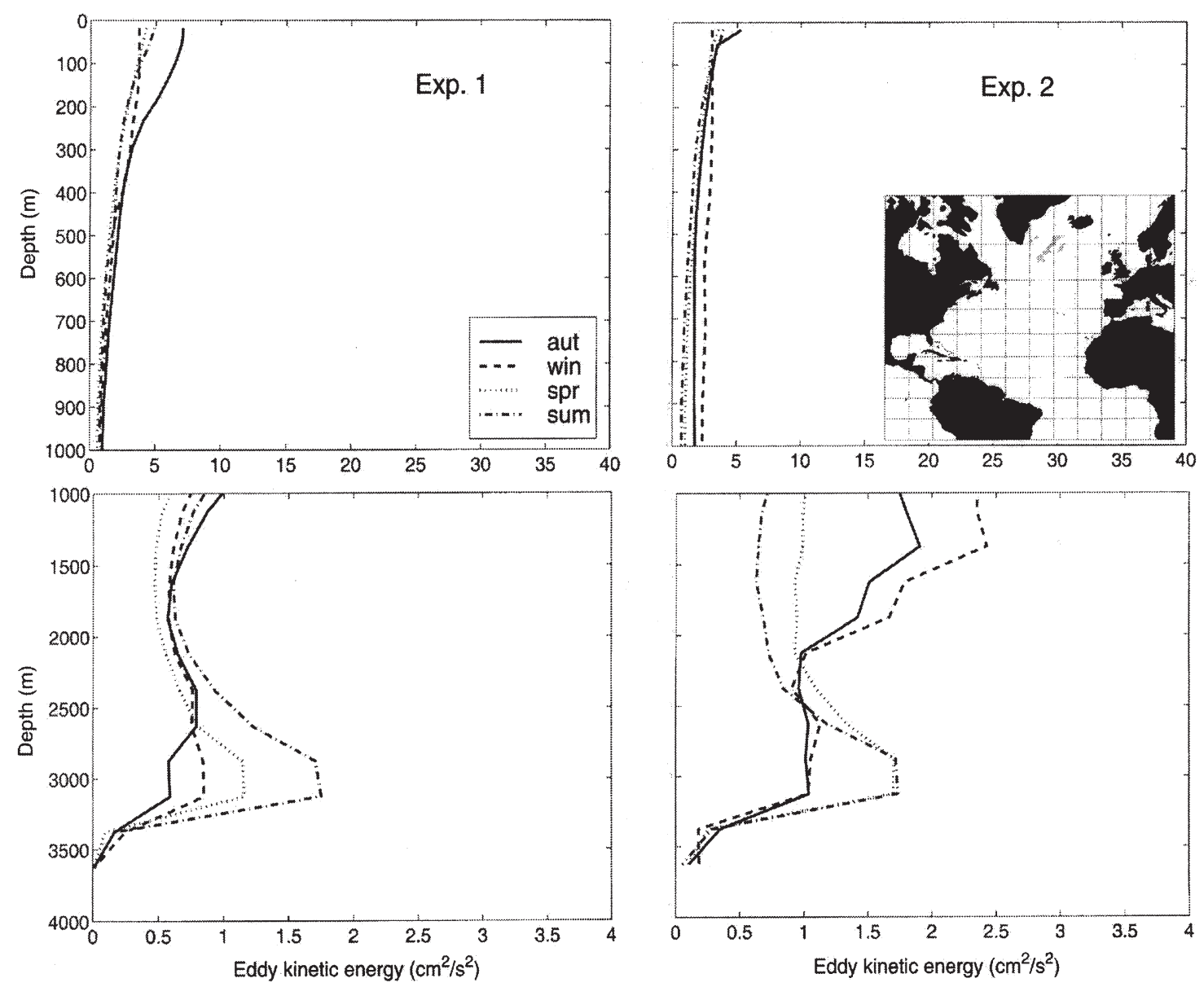

Fig. 9. Seasonal profiles of $K_{\mathrm{E}}$, similar to Fig. 6, but for region IS.

variation in high-energy regions covering the Gulf Stream Extension, NAC and NEC, it leads to a marked difference between winter and summer energies in the low energy areas away from these baroclinically unstable regimes. An important characteristic of this wind-induced variability is its weak depth dependence, with a winter to summer difference approximately constant over almost the whole water column.

\section{5. $K_{\mathrm{E}}$ changes and wind stress forcing}

The relation between the seasonally varying $K_{\mathrm{E}}$ amplitudes and the wind variability has been examined by computing the correlation coefficient of the variance of the absolute daily wind stress $|\tau|$ over the seasons with the seasonal $K_{\mathrm{E}}$ anomalies from Experiment 2. Results are shown in Fig. 14 for depths of (a) $91 \mathrm{~m}$, (b) $900 \mathrm{~m}$ and (c) $2125 \mathrm{~m}$. Sections of the same correlation are presented in Fig. 15 along $58^{\circ} \mathrm{N}$ (Fig. 15a), $51^{\circ} \mathrm{N}$ (Fig. 15b), and $30^{\circ} \mathrm{W}$ (Fig. 15c). 

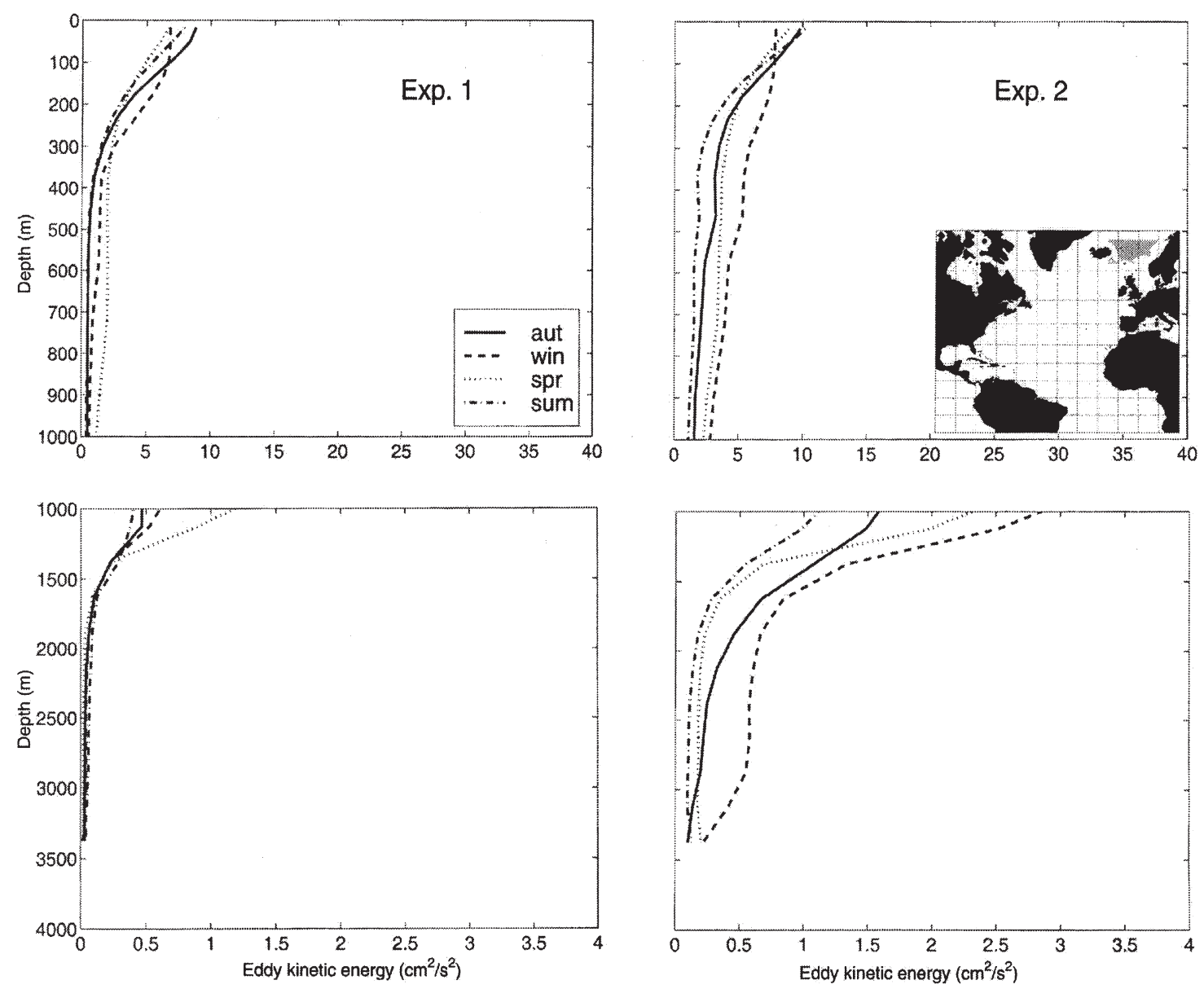

Fig. 10. Seasonal profiles of $K_{\mathrm{E}}$, similar to Fig. 6, but for region NW.

There is remarkable agreement with previous results from T/P data, with the regions showing high correlation between near-surface energy changes and fluctuating winds being confined to the northern and north-eastern North Atlantic, and (for entirely different reasons) to the tropics. Deeper into the water column, these areas become more extensive compared to the surface conditions, and wider to include much of the eastern North Atlantic (east of the MAR), the Labrador Sea, the and Greenland Sea.

Comparisons of Fig. 4, Fig. 14 and Fig. 15 reveals that maxima in the correlation occur in all those areas where the level of background energy is low, and thus permits an enhancement of the relative importance of wind-induced energy. In contrast, neither the NAC and nor the NEC exhibit such similar correlations in either the model outputs or the altimetric data; this implies a dominance of other energy sources, such as baroclinic instability.

The quantitative effect of variable wind forcing on eddy generation in the low- $K_{\mathrm{E}}$ areas in the model is summarized in Fig. 16. It shows zonal averages in the difference in $K_{\mathrm{E}}$ between winter and summer between Experiment 1 and 2. Fields are averaged over the shaded regions shown in 

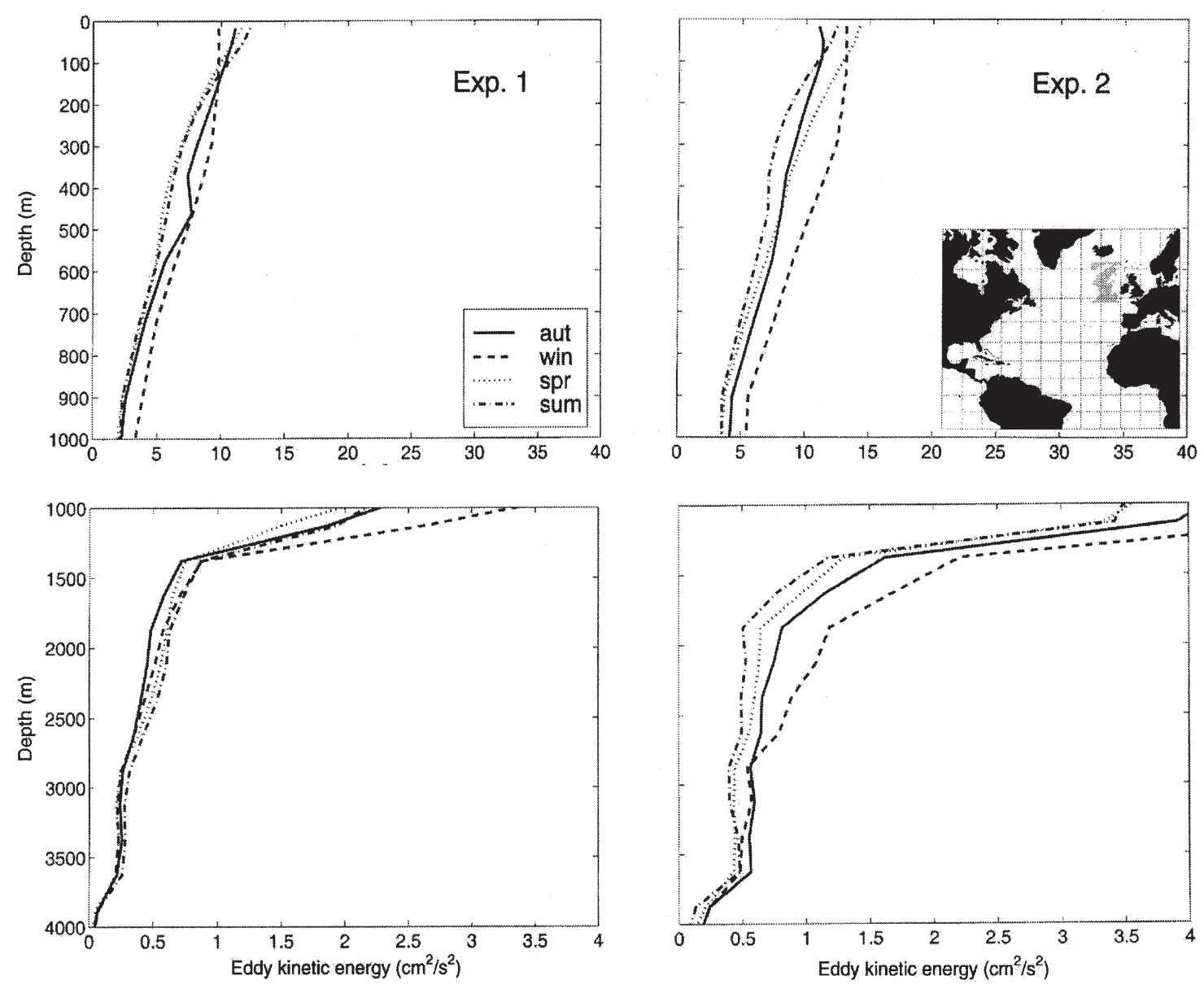

Fig. 11. Seasonal profiles of $K_{\mathrm{E}}$, similar to Fig. 6, but for region $\mathrm{NEA}_{\mathrm{N}}$.

the inset (i.e., the low- $K_{\mathrm{E}}$ areas, basically east of $40^{\circ} \mathrm{W}$ ). The left panel represents the depth range 1000-2500 m, and the right panel illustrates the corresponding results for the depth range 2500$4000 \mathrm{~m}$. No seasonal variation in the eddy energy is obtained in Experiment 1 with monthly wind forcing, but in Experiment 2 the daily wind forcing simulates energy levels, which in winter months significantly exceed the summer values over a wide latitude range. A marked quantitative difference is seen especially north of $50^{\circ} \mathrm{N}$, apparently associated with the maximum in winterto-summer difference in the variance of the wind stress, associated with the general path of winter storm systems (Fig. 13b).

\section{Conclusions}

The model has insufficient resolution to simulate quantitatively the observed energy levels at mid- and higher latitudes. Nonetheless it succeeds in reproducing the major features of the 

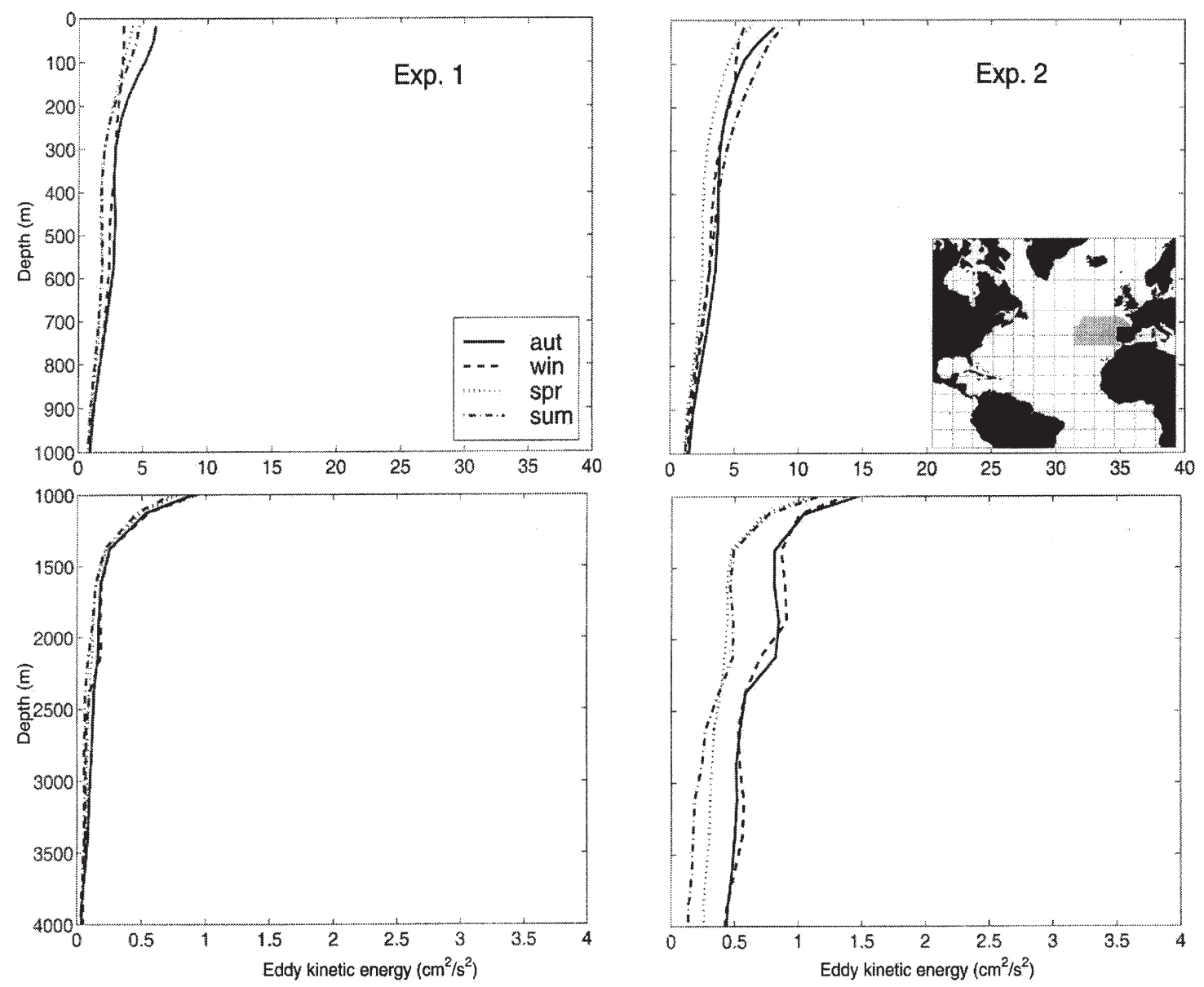

Fig. 12. Seasonal profiles of $K_{\mathrm{E}}$, similar to Fig. 6, but for region NEAs.

observed distribution of mean eddy kinetic energy, such as the concentration of energy along the branches of the North Atlantic Current (DYNAMO Group, 1997; Willebrand et al., 2001). The emphasis of this analysis has been on the changes in eddy kinetic energy between experiments with differing wind forcing: the comparison of an experiment with monthly mean forcing and an experiment with daily wind stresses has allowed us to address the question of the contribution of variable wind forcing to the generation of eddy energy. The pair of experiments has been complemented by a spin-down experiment in which there was no wind forcing; which allowed us to check on alternate sources of 'eddy' energy, e.g., deep buoyancy driven flow variations in the Labrador Sea.

The question of a seasonal variation in near-surface eddy fields has been addressed previously in several studies using altimeter data. Early results based on GEOSAT data for the North Atlantic indicated seasonality in height variations in the subtropical North Atlantic, with a maximum occurring during fall (September to November), i.e., showing a lack of correspondence with the seasonal cycle in the variance of the wind stress (Zlotnicki, Fu \& Patzert, 1989; Stammer, 1992). However, 

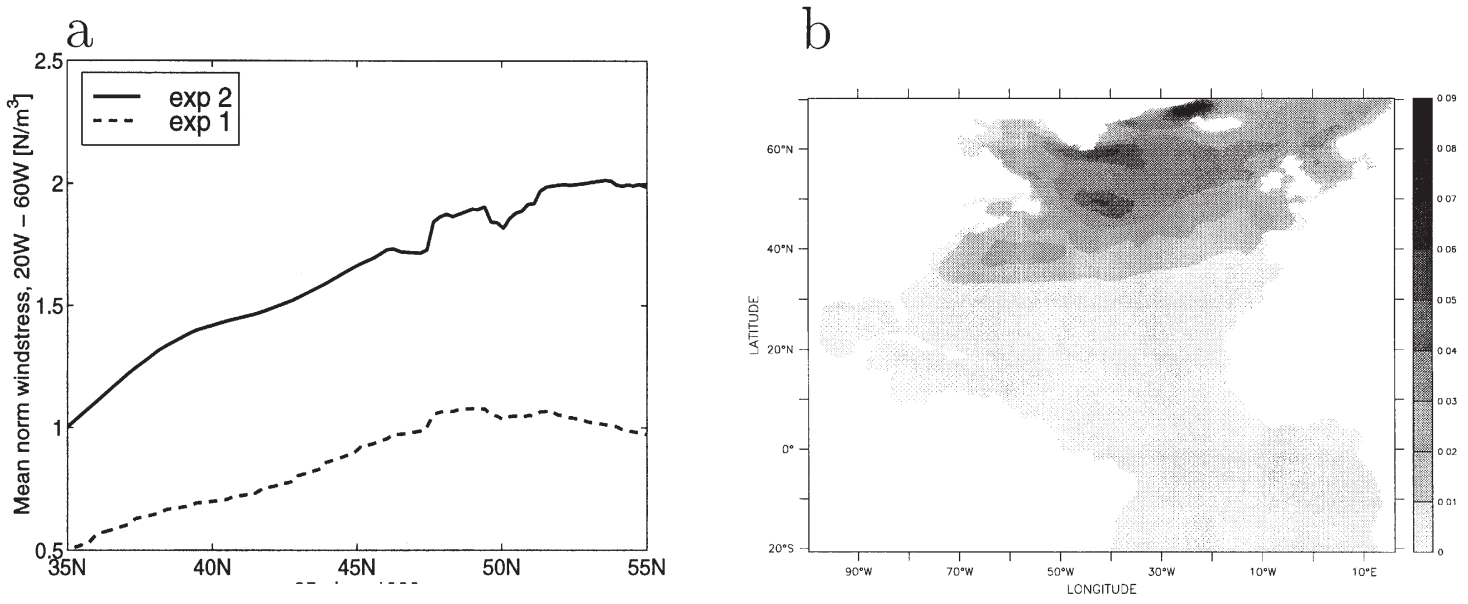

Fig. 13. (a) Zonal averages of the zonal wind stress $\left|\tau_{\kappa}\right|$ in summer, used in the forcing of Experiment 1 and Experiment 2. Values are averaged between $20^{\circ} \mathrm{W}$ and $60^{\circ} \mathrm{W}$. (b) Variance of the daily norm wind stress fields from the period 1990-1993. Note that this field is dominated by the enhanced winter variability.

these early findings were subsequently revised in studies based on the more precise TOPEX/POSEIDON data by White and Heywood (1995) for the northern Atlantic and in a comprehensive, global analysis by SW99. These studies revealed a very complex pattern to the changes in eddy variability, apparently related both to wind generation and to baroclinic instability processes.

Since the high frequency variance of the wind stress curl at mid- and higher latitudes is much larger during the winter season, an ocean variability component forced by high-frequency wind fields must be manifested in an annual modulation of eddy kinetic energy. The seasonal cycle in eddy energy obtained in the model is significantly different between the cases with monthly mean and with daily wind forcing. In the daily forcing case, the model simulates a seasonal cycle, in general agreement with the observational evidence based on analyses of both altimeter and deep current meter data. In particular, eddy energy levels are enhanced during winter in similar areas to those identified in the T/P study by SW99. This reinforces a main conclusion of the SW99 study: that significant wind impact on the generation of eddy energy is confined mainly to the northern North Atlantic (including the Labrador Sea, the Irminger Sea, and the north-eastern part of the basin). All these regions are characterized by a weak stratification and low near-surface background eddy variability. They are also subjected to a higher variance in the winter wind stresses than is the subtropical ocean. Both factors conspire to allow the relatively small windinduced eddy component to be detected against the background of internally-induced variability, which greatly exceeds the wind effects in the vicinity of the major open ocean frontal systems.

Fig. 17a summarizes the near-surface regions for which the model yields a significant correlation between the seasonal cycles of the local eddy energy and the variance of the local wind stress. A main feature of the wind-induced signal indicated in the model solution is that its amplitude is only weakly depth-dependent. Since the mean eddy energy level generally decreases with depth, the relative importance of the wind-induced signal becomes greater at deeper levels. A manifestation of this dependence is the considerable expansion with the increasing depth of those 

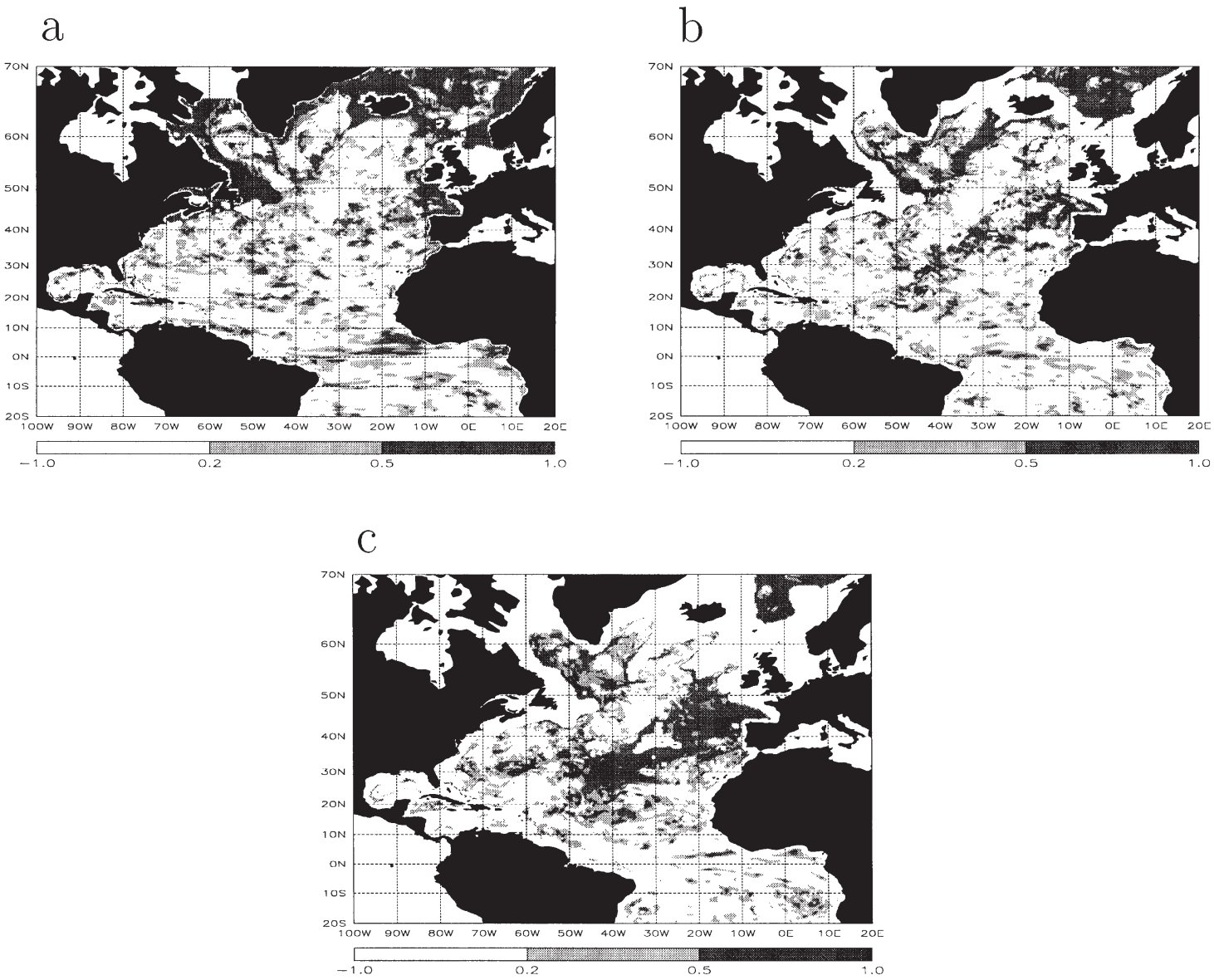

Fig. 14. Correlation coefficient of the variance of the absolute wind stress $|\tau|$ over individual seasons with seasonal $K_{\mathrm{E}}$ anomaly fields from Experiment 2 obtained at (a) $91 \mathrm{~m}$ depth, (b) $9000 \mathrm{~m}$ depth and (c) $2125 \mathrm{~m}$ depth, respectively.

regions (Fig. 17b) exhibiting a significant correlation between local eddy energy and local wind stress variability. This is especially the case in the northeastern part of the basin, reflecting the very small background variability there. In contrast, all the blank regions in the figure show where there are no major seasonal variations in eddy kinetic energy. Near the surface, these regions cover the bulk of the basin, including the Gulf Stream and North Atlantic Current system, the western subtropical gyre and the NEC, for which internal flow instability mechanisms appear to be the primary eddy generation mechanism. At depth, the imprint of these current features is still visible in the correlation map, but is considerably reduced compared to the surface.

While the model results are consistent with the altimeter observations with respect to the patterns and phases of the annual changes in eddy variability, they disagree with respect to their amplitude. Results from WH and SW99 suggest that in the LS and the eastern North Atlantic the annual amplitude of $K_{\mathrm{E}}$ is up to $30-40 \mathrm{~cm}^{2} \mathrm{~s}^{2}$, whereas the model estimates are lower by more than a factor of 10 in their seasonal $K_{\mathrm{E}}$ amplitude. On the other hand, the model amplitudes at depth, with winter-to-summer differences on the order of $1-3 \mathrm{~cm}^{2} \mathrm{~s}^{2}$ in the northern North 
(a)

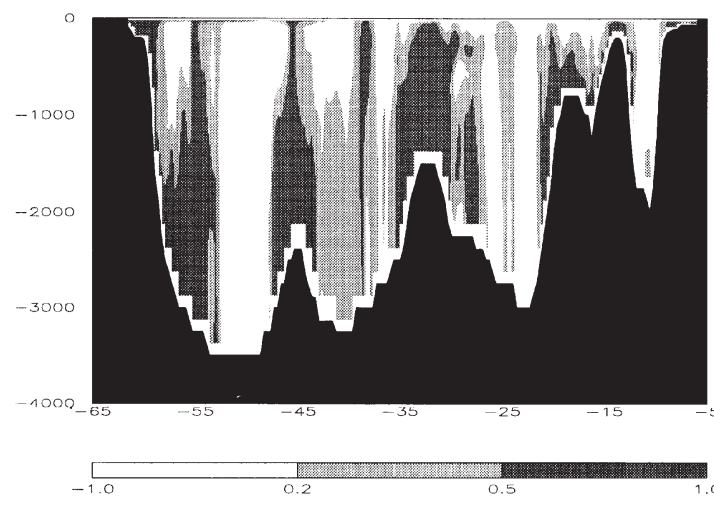

(b)

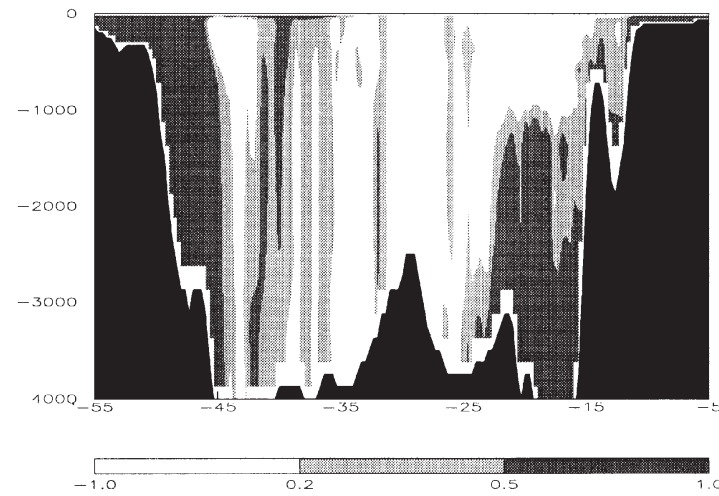

(c)
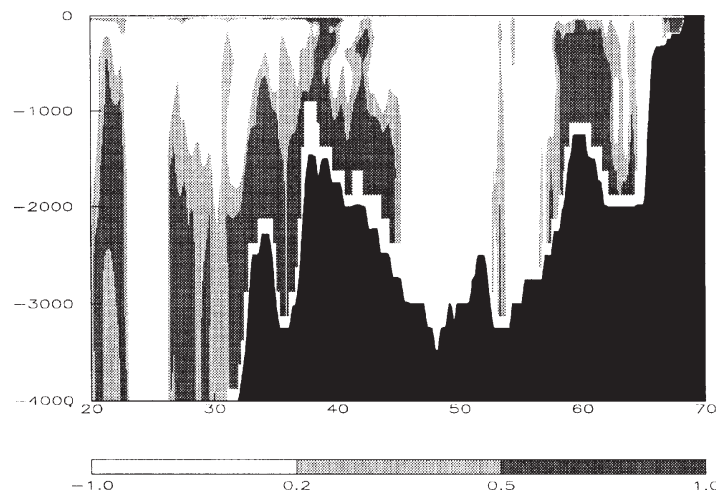

Fig. 15. Vertical sections of the correlation coefficient of $K_{\mathrm{E}}$ in the DYNAMO model with the absolute wind stress $|\tau|$ along (a) $58^{\circ} \mathrm{N}$, (b) $51^{\circ} \mathrm{N}$, and (c) $30^{\circ} \mathrm{W}$, respectively.
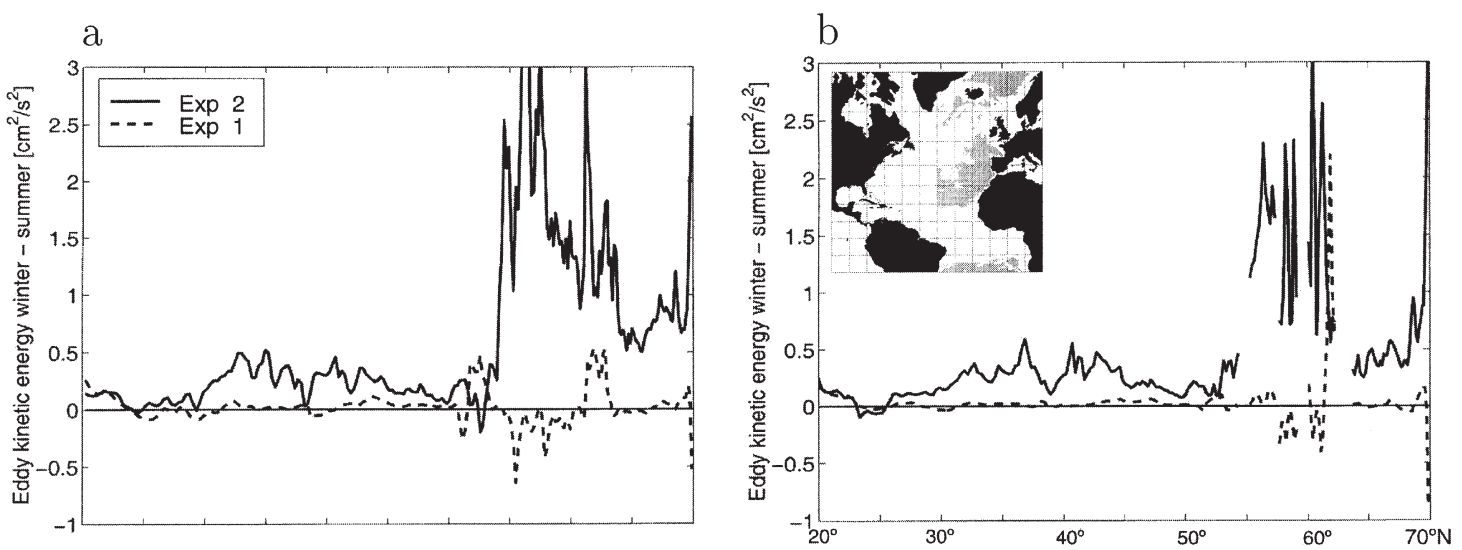

Fig. 16. Zonal averages of the difference in $K_{\mathrm{E}}$ between winter and summer in Experiment 1 and Experiment 2 . Fields are averaged over the shaded regions shown in the inset (basically east of $40^{\circ} \mathrm{W}$ ). The left panel shows results for the depth range 1000-2500 $\mathrm{m}$; the right panel the range $2500-4000 \mathrm{~m}$. 

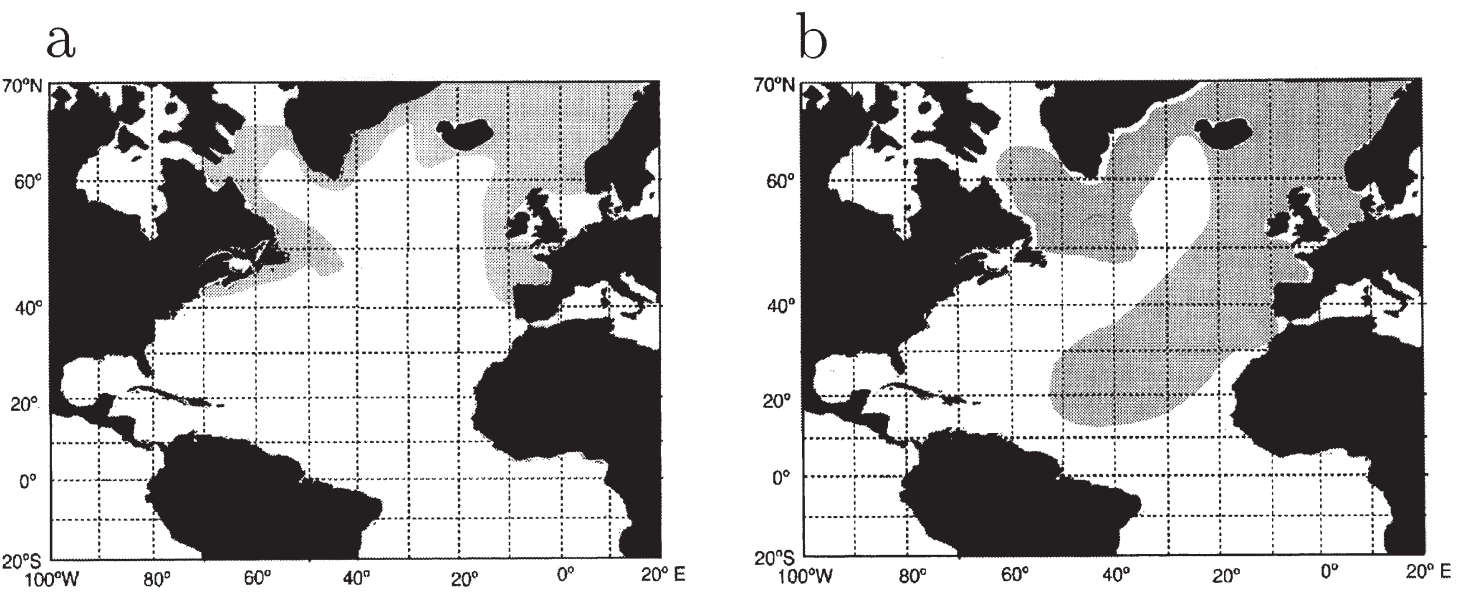

Fig. 17. Shaded areas mark regions where a high correlation was found between seasonal $K_{\mathrm{E}}$ anomaly fields and the variance of the absolute wind stress; left: near-surface (51); right: at depth $(2100 \mathrm{~m})$.

Atlantic, compare well with the evidence from deep current meter records: e.g., both Dickson et al. (1982) for the northeastern North Atlantic and Koblinsky et al. (1989) reported changes of O $\left(1 \mathrm{~cm}^{2} \mathrm{~s}^{2}\right)$ between winter and summer $K_{\mathrm{E}}$ levels.

There are two potential shortcomings in the present model whose significance, in particular, for the amplitude of the seasonal changes cannot readily be assessed. The first is the effect of the model grid size being insufficient to resolve the eddy spectrum at high latitudes. This is known to be the main cause of deficits in the mean eddy kinetic energy, i.e., the part resulting from instability mechanisms (Smith, Maltrud, Bryan \& Hecht, 1999), but its effect on the quasi-linear response of the ocean to high-frequency wind forcing is unclear. The second potential shortcoming is that the wind stress fields from forecast centers such as the ECMWF used in the present case, lack variance at high wavenumbers, which by itself can lead to a substantial underestimate of wind effects in the model (Millif, Large, Holland \& McWilliams, 1996).

\section{Acknowledgements}

D.S. was supported in part by Contract 958125 with the Jet Propulsion Laboratory, and Grant NAGW-7162 with the National Aeronautics and Space Administration. Contribution to WOCE. The model development and integration has been part of the DYNAMO project which has been supported by the European Union MAST-2 programme under contract no. MAS2-CT93-0060.

\section{References}

Barnier, B., Reynaud, T., Beckmann, A., Böning, C., Molines, J.-M., Barnard, S., \& Jia, Y. (2001). On the seasonal variability and eddies in the North Brazil Current: insights from model intercomparison experiments. Progress in Oceanography, 48, 195-230. 
Beckmann, A., Böning, C. W., Brügge, B., \& Stammer, D. (1994). On the generation and role of eddy variability in the central North Atlantic Ocean. Journal of Geophysical Research, 99, 20381-20391.

Böning, C., Dieterich, C., Barnier, B., \& Jia, Y. (2001). Seasonal cycle of meridional heat transport in the subtropical North Atlantic: a model intercomparison in relation to observations near $25^{\circ} \mathrm{N}$. Progress in Oceanography, 48 , 231-253.

Brink, K. H. (1989). Evidence for wind-driven current fluctuations in the western North Atlantic. Journal of Geophysical Research, 94, 2029-2044.

Brügge, B. (1995). Near surface mean circulation and eddy kinetic energy in the central North Atlantic from drifter data. Journal of Geophysical Research, 100, 20543-20554.

Chave, A. D., Luther, D. S., \& Filloux, J. H. (1992). The barotropic electromagnetic and pressure experiment 1. Barotropic current response to atmospheric forcing. Journal of Geophysical Research, 97, 9565-9593.

Dickson, R. R., Gould, W. J., Gurbutt, P. A., \& Killworth, P. D. (1982). A seasonal signal in ocean currents to abyssal depths. Nature, London, 295, 193-198.

DYNAMO Group (1997). DYNAMO: dynamics of North Atlantic Models: simulation and assimilation with high resolution models. Report Nr. 294, Institut für Meereskunde, Kiel, Germany.

Frankignoul, C., \& Müller, P. (1979). Quasi-geostrophic response of an infinite beta-plane ocean to stochastic forcing by the atmosphere. Journal of Physical Oceanography, 9, 104-127.

Fu, L.-L., Keffer, T., Niller, P. P., \& Wunsch, C. (1982). Observations of mesoscale variability in the western North Atlantic: a comparative study. Journal of Marine Research, 40, 809-847.

Fu, L.-L., \& Smith, R. D. (1996). Global ocean circulation from satellite altimetry and high-resolution computer simulation. Bulletin of the American Meteorological Society, 77, 2625-2636.

Fukumori, I., Raghunath, R., \& Fu, L.-L. (1998). Nature of global large-scale sea level variability in relation to atmospheric forcing: a modeling study. Journal of Geophysical Research, 103, 5493-5512.

Gill, A. E., Green, J. S. A., \& Simmons, A. J. (1974). Energy partition in the large-scale ocean circulation and the production of mid-ocean eddies. Deep Sea Research, 21, 499-528.

Jayne, S. R., \& Tokmakian, R. (1997). Forcing and sampling of ocean general circulation models: impact of highfrequency motions. Journal of Physical Oceanography, 27, 1173-1179.

Koblinsky, C. J., \& Niller, P. P. (1982). The relation between deep ocean currents and winds east of Barbados. Journal of Physical Oceanography, 12, 144-153.

Koblinsky, C. J., Niller, P. P., \& Schmitz, W. J. Jr (1989). Observations of windforced deep-ocean currents in the North Pacific. Journal of Geophysical Research, 94, 10773-10790.

Large, W. G., Holland, W. R., \& Evans, J. C. (1991). Quasi-geostrophic ocean response to real wind forcing: the effects of temporal smoothing. Journal of Physical Oceanography, 21, 998-1017.

Luther, D. S., Chave, A. D., Filloux, J. H., \& Spain, P. F. (1990). Evidence for local and nonlocal barotropic responses to atmospheric forcing during BEMPEX. Geophysical Research Letters, 17, 949-952.

Marshall, J., \& Schott, F. (1999). Open ocean deep convection: observations, models and theory. Revue of Geophysics, 37, 1-64.

Mercier, H., \& Colin de Verdiere, A. (1985). Space and time scales of mesoscale motions in the eastern North Atlantic. Journal of Physical Oceanography, 15, 171-183.

Millif, R. F., Large, W. G., Holland, W. R., \& McWilliams, J. C. (1996). The general-circulation responses of highresolution North Atlantic models to synthetic-scatterometer wind. Journal of Physical Oceanography, 26, 17471768.

Müller, P., \& Frankignoul, C. (1981). Direct atmospheric forcing of geostrophic eddies. Journal of Physical Oceanography, 11, 287-308.

Müller, T. J., \& Siedler, G. (1992). Multi-year current time series in the North Atlantic Ocean. Journal of Marine Research, 50, 63-98.

New, A. L., Barnard, S., Herrmann, P., \& Molines, J.-M. (2001a). On the origin and pathway of the saline inflow to the Nordic Seas: insights from models. Progress in Oceanography, 48, 255-287.

New, A. L., Jia, Y., Coulibaly, M., \& Dengg, J. (2001b). On the role of the Azores Current in the ventilation of the North Atlantic Ocean. Progress in Oceanography, 48, 163-194.

Niller, P. P., \& Koblinsky, C. (1985). A local time-dependent Sverdrup balance in the northeast Pacific. Science, 229, 754-756. 
Pacanoswski, R.C., Dixon, K., Rosati, A. (1991). The G.F.D.L. Modular Ocean Model user guide. Technical Report 2, GFDL Ocean Group.

Richardson, P. L. (1983). Eddy kinetic energy in the North Atlantic from surface drifters. Journal of Geophysical Research, 88, 4355-4367.

Samelson, R. M. (1990). Evidence for wind-driven current fluctuations in the eastern North Atlantic. Journal of Geophysical Research, 95, 11359-11368.

Smith, R. D., Maltrud, M. E., Bryan, F. O., \& Hecht, M. W. (1999). Numerical simulation of the North Atlantic Ocean at $1 / 10^{\circ}$. Journal of Physical Oceanography, 30, 1532-1561.

Stammer, D., (1992). Über die mesoskalige Variabilität im Atlantischen Ozean - Analyse und Assimilation von GEOSAT-Altimeterdaten. Ph.D. Thesis, University Kiel. git Berichte Inst. Meereskunde Kiel, 224, 210 pp.

Stammer, D. (1997). Global characteristics of ocean variability from regional TOPEX/POSEIDON altimeter measurements. Journal of Physical Oceanography, 27, 1743-1769.

Stammer, D. (1998). On eddy characteristics, eddy transports and mean flow properties. Journal of Physical Oceanography, 28, 727-739.

Stammer, D., \& Böning, C. (1996). Generation and distribution of mesoscale eddies in the North Atlantic Ocean. In W. Krauss, Warmwatersphere of the North Atlantic Ocean (pp. 159-193). Berlin: Gebrüder Bornträger.

Stammer, D., \& Wunsch, C. (1999). Temporal changes in eddy energy of the oceans. Deep Sea Research II, 46, 77-108.

White, M. A., \& Heywood, K. J. (1995). Seasonal and interannual changes in the North Atlantic subpolar gyre from GEOSAT and TOPEX/POSEIDON altimetry. Journal of Geophysical Research, 101, 24931-24942.

White, M. A., \& Heywood, K. J. (1995). Seasonal and interannual changes in the North Atlantic subpolar gyre from GEOSAT and TOPEX/POSEIDON altimetry. Journal of Geophysical Research, 101, 24931-24942.

Willebrand, J., Barnier, B., Böning, C., Dieterich, C., Killworth, P. D., Le Provost, C., Jia, Y., Molines, J.-M., \& New, A. L. (2001). Circulation characteristics in three eddy-permitting models of the North Atlantic. Progress in Oceanography, 48, 123-161.

Willebrand, J., Philander, S. G. H., \& Pacanowski, R. C. (1980). The oceanic response to large-scale atmospheric disturbances. Journal of Physical Oceanography, 10, 411-429.

Wunsch, C. (1997). The vertical partition of horizontal kinetic energy and the spectrum of global variability. Journal of Physical Oceanography, 27, 1770-1794.

Wunsch, C., \& Stammer, D. (1995). The global frequency-wavenumber spectrum of oceanic variability estimated from TOPEX/POSEIDON altimeter measurements. Journal of Geophysical Research, 100, 24895-24910.

Wunsch, C., \& Stammer, D. (1998). Satellite altimetry, the marine geoid and the oceanic general circulation. Annual Reviews of Earth and Planetary Sciences, 26, 219-253.

Zlotnicki, V., Fu, L.-L., \& Patzert, W. (1989). Seasonal variability in global sea level observed with GEOSAT altimetry. Journal of Geophysical Research, 95, 17959-17970. 